\title{
The Song Remains the Same: A Replication and Extension of the MUSiC Model
}

Peter J. Rentfrow

University of Cambridge, Cambridge, United Kingdom

Lewis R. Goldberg

Oregon Research Institute

David J. Stillwell \& Michal Kosinski

University of Cambridge, Cambridge, United Kingdom

Samuel D. Gosling

University of Texas at Austin

\section{DANiEL J. LeVitin}

McGill University, Montreal, Canada

THERE IS OVERWHELMING ANECDOTAL AND EMPIRICAL evidence for individual differences in musical preferences. However, little is known about what drives those preferences. Are people drawn to particular musical genres (e.g., rap, jazz) or to certain musical properties (e.g., lively, loud)? Recent findings suggest that musical preferences can be conceptualized in terms of five orthogonal dimensions: Mellow, Unpretentious, Sophisticated, Intense, and Contemporary (conveniently, MUSIC). The aim of the present research is to replicate and extend that work by empirically examining the hypothesis that musical preferences are based on preferences for particular musical properties and psychological attributes as opposed to musical genres. Findings from Study 1 replicated the five-factor MUSIC structure using musical excerpts from a variety of genres and subgenres and revealed musical attributes that differentiate each factor. Results from Studies 2 and 3 show that the MUSIC structure is recoverable using musical pieces from only the jazz and rock genres, respectively. Taken together, the current work provides strong evidence that preferences for music are determined by specific musical attributes and that the MUSIC model is a robust framework for conceptualizing and measuring such preferences.

Received September 28, 2011, accepted March 20, 2012.

Key words: music, preferences, individual differences, factor analysis, genres
W HAT IS IT ABOUT MUSIC THAT PEOPLE LIKE SO much? Is it the sound, the feelings it evokes, or the images it conjures up? Music is so central to human life and elicits such varied reactions that it is hard to know which aspects of it underlie preferences. Theory and research in music psychology has focused considerable attention on the effects that music can have on cognitive, physiological, and neurological processes. We know that when individuals listen to their favorite music, they experience "chills" or "shivers" (Grewe, Kopiez, \& Altenmüller, 2009; Sloboda, 1991), heightened levels of positive affect (Schellenberg, Peretz, \& Vieillard, 2008; Sloboda \& O'Neill, 2001; Zentner, Grandjean, \& Scherer, 2008) that may be accompanied by dopamine release (Menon \& Levitin, 2005), and mental stimulation (Emery, Hsiao, Hill, \& Frid, 2003; George, Stickle, Rachid, \& Wopnford, 2007; Rickard, Toukhsati, \& Field, 2005). We also know that people use their favorite music as an identity badge to broadcast information about themselves to others and that such social messages influence how individuals are perceived (Rentfrow \& Gosling, 2006, 2007; Rentfrow, McDonald, \& Oldmeadow, 2009). Appreciation for music is regarded as a human cultural universal (Brown, 2004; Cross, 2001) and remains intact even in individuals with neurodevelopmental impairment (Levitin \& Bellugi, 1998; Levitin et al., 2004). Curiously, despite the overwhelming evidence that listening to music can have a variety of important effects, we know very little about why people like the music they do. Which aspects of music shape preferences?

The overarching aim of the present research program is to broaden our understanding of the nature of musical preferences. Toward that end, the current investigation set out to examine which aspects of music underlie individual differences in musical preferences. Specifically, we argue that research on individual differences in musical preferences has been limited by conceptual and methodological constraints that have hindered our understanding of the psychological and social factors underlying preferences in music. This work attempts to correct those methodological

Music Perception volume 30, issue 2, PP. 161-185. ISSN 0730-7829, ELECTRONIC ISSN 1533-8312. () 2012 BY THE REGENTS OF THE UNIVERSity OF CALIFORNIA ALL RIGHTS RESERVED. PLEASE DIRECT ALL REQUESTS FOR PERMISSION TO PHOTOCOPY OR REPRODUCE ARTICLE CONTENT THROUGH THE UNIVERSITY OF CALIFORNIA PRESS'S RIGHTS AND PERMISSIONS WEBSITE, HTTP://WWW.UCPRESSJOURNALS.COM/REPRINTINFO.ASP.DOI: 10.1525/MP.2012.30.2.161 
shortcomings with the goal of advancing theory and research in this area.

\section{The Structure of Musical Preferences}

Cattell and Anderson (1953) were among the first investigators to systematically examine individual differences in musical preferences. To do so, they developed a musical preference test consisting of 120 classical and jazz music excerpts, to which respondents reported their degree of liking (Cattell \& Anderson, 1953; Cattell \& Saunders, 1954). Factor analyses of preference ratings for the excerpts suggested 12 music-preference factors, which Cattell interpreted as dimensions of unconscious personality traits. For instance, preferences for excerpts of fast musical pieces defined one factor, labeled surgency, and preferences for excerpts of slow, melancholic musical pieces defined another factor, labeled sensitivity. Cattell's interest in studying musical preferences had more to do with developing a method for measuring unconscious aspects of personality than with musical preferences. Specifically, Cattell posited that music evokes visceral responses that are outside conscious control; hence musical preferences were thought to reflect unconscious needs, urges, and conflicts. However, given the inherent difficulty of empirically validating unconscious processes and the growing skepticism surrounding individual differences at the time, Cattell's music research had no impact on mainstream psychology.

Only recently have researchers returned to examining the structure of individual differences in musical preferences. Unlike Cattell, however, current researchers are expressly interested in understanding the psychological basis of musical preferences. The assumption underlying much of this work is that individuals seek musical environments that reinforce and reflect aspects of their personalities, attitudes, and emotions (Colley, 2008; Delsing, ter Bogt, Engels, \& Meeus, 2008; George et al., 2007; Rentfrow \& Gosling, 2003; Rentfrow \& McDonald, 2009; Schäfer \& Sedlmeier, 2009). Much of the research in this area has examined the structure of musical preferences with the aim of developing a foundation on which to develop and test hypotheses about the role of music in everyday life.

Nearly a dozen independent investigations have examined the structure of musical preferences. Most of these investigations assessed individual differences in preferences using music-genre labels (e.g., classical, rock, rap, etc.) as proxies for listening to actual musical pieces. Despite using highly similar methods, there was little consensus about which genre labels to study or how many to measure - some studied as few as 11 (e.g., Colley, 2008; Delsing et al., 2008) and others as many as
30 genre labels (e.g., George et al., 2007). Nevertheless, results across these studies showed some degree of convergence at approximately five music-preference dimensions (Colley, 2008; Delsing et al., 2008; Dunn, de Ruyter, \& Bouwhuis, 2012; George et al., 2007; Rentfrow \& Gosling, 2003; Rentfrow \& McDonald, 2009; Schäfer \& Sedlmeier, 2009). Careful examination of the factor structures reported across these studies suggests that there is one factor defined mainly by preferences for classical and jazz music; another factor defined by preferences for rock and heavy metal music; a third factor defined by preferences for rap and hip-hop music; a fourth factor comprising mainly preferences for country music; and a fifth factor composed mostly of preferences for new age and electronic styles of music.

These convergent findings are encouraging because they suggest that there is a robust structure underlying individual differences in musical preferences. However, a limitation of the work is that the studies situated their experiments within the system of music genre labels as defined by the recording and retail music industries. Although genres represent a level of analysis that most people are familiar with (Rentfrow \& Gosling, 2003) retail stores have been classifying music this way for 50 years - the genre categories themselves are neither logically constructed nor coherent. For example, Frank Sinatra might be found under any of the following categories: Popular, Male Vocal, Big Band, Swing, Easy Listening, Broadway, or Jazz. Indeed, in some cases, different albums by Sinatra would be classified under different headings. AC/DC and Van Halen were once considered Heavy Metal and now are considered Classic Rock. The music of Rosanne Cash has more in common with the folk-rock of early Joni Mitchell and James Taylor than the country label under which her music is typically found, due to accidents of history, birth, and the vagaries of the industry. In pilot work, we found that participants did not always agree on the genre and subgenre labels under which even their own favorite music should be placed. Thus, measurements based solely on genre labels are necessarily crude and imprecise. To push the point further, it is evident that individuals who like, for instance, classical music, do not like all classical music, and furthermore, they may like select pieces of jazz, pop, and soul. Thus a model that relies heavily on the vague and heterogeneous classification of genre labels is clearly missing an important aspect of musical preferences - aspects of the music itself, and its social construal.

Furthermore, the heterogeneity of genres means that they fail to index music's many facets; relying solely on genre labels makes it hard to know which aspects of 
music influence preferences. Listeners could be drawn to auditory and psychological properties that are intrinsic to the music, such as timbre, pitch, or intensity. These in turn, especially when combined with lyrics, can give rise to specific emotional reactions to the music that are genre-independent. Or they could be influenced by social connotations that are extrinsic to the music, such as whether the music is regarded as "cool" or "appropriate" for one's social identity or group. In other words, it seems logical to assume that similar emotional reactions might occur to musical pieces from different genres, and different reactions might occur to musical pieces from within the same genre. Thus, our aim was not to abandon the genre-based selection of experimental music entirely, but rather, to develop new measurement approaches that would allow us to access the diversity of music that exists within a genre, and those latent cross-genre consistencies that may exist.

What might such cross-genre consistencies look like? There has been no comprehensive systematic analysis of how different facets of music shape musical preferences, but the available research suggests that there are individual differences in preferences for vocal as opposed to instrumental music, fast vs. slow music, and loud vs. soft music (Kopacz, 2005; McCown, Keiser, Mulhearn, \& Williamson, 1997; McNamara \& Ballard 1999; Rentfrow \& Gosling, 2006). There is also emerging evidence of individual differences in preferences for pieces of music that evoke or signify emotions such as happiness, joy, sadness, and anger (Rickard, 2004; Schellenberg et al., 2008; Zentner et al., 2008). And there is evidence that individuals are drawn to musical styles with particular social connotations, such as toughness, rebellion, distinctiveness, and sophistication (Abrams, 2009; Schwartz \& Fouts, 2003; Tekman \& Hortaçsu, 2002). Taken together, these findings clearly point to the need to assess musical preferences using a method that captures the many auditory and psychological aspects of music.

To address this need and establish a robust framework of musical preferences, Rentfrow, Goldberg, and Levitin (2011) recently examined individual differences in musical preferences by playing audio recordings of real music taken from a range of genres to experimental participants. Specifically, in three independent studies, participants were presented with $15 \mathrm{~s}$ audio excerpts of actual musical pieces and asked to indicate their degree of liking for each excerpt. The pieces used in the studies were different. In Study 1, the excerpts were from commercially released musical pieces and in Studies 2 and 3 the excerpts were from commercially unreleased musical pieces obtained from Getty Images. To identify the characteristics that defined and differentiated each of the preference dimensions, the musical pieces used in all three studies were rated by independent coders on seven auditory attributes (e.g., distorted, fast, loud) and seven psychological attributes (e.g., aggressive, intelligent, romantic).

Factor analyses of the music-preference data from each of the three studies converged to reveal five robust music-preference dimensions. Analyses of the auditory and psychological attributes associated with the pieces provided clues about the properties that defined each of the factors and provided a foundation for interpreting them. The first factor was defined by pieces of music that coders described as romantic, relaxing, unaggressive, sad, slow, and quiet, and from the genres the music industry labels soft rock, R \& B, and adult contemporary; on the basis of those results, we labeled this factor Mellow (or relaxed, slow, and romantic). The second factor was defined by pieces of music that were coded as uncomplicated, relaxing, unaggressive, soft, and acoustic, and primarily from the country, folk, and singer/songwriter music genres; on the basis of those findings, we labeled this factor Unpretentious (or uncomplicated, unaggressive, and soft sounding). The third factor was defined by pieces of music that were coded as inspiring, intelligent, complex, and dynamic, and were from the classical, operatic, avant-garde, world beat, and traditional jazz music genres; given those results, we labeled this factor Sophisticated (or complex, intelligent, and cultured). The fourth factor was defined by pieces of music that were coded as distorted, loud, aggressive, and not relaxing, romantic, nor inspiring, and were from the classic rock, punk, heavy metal, and power pop music genres; the characteristics of that factor led us to label it Intense (or loud, aggressive, and tense). The fifth factor was defined by pieces of music that were coded as percussive, electric, and not sad, and from the rap, electronica, Latin, acid jazz, and Euro pop music genres; on the basis of those results, we labeled the factor Contemporary (or current, rhythmic, and danceable). Taken together, the results suggested that preferences for Mellow, Unpretentious, Sophisticated, Intense, and Contemporary (or MUSIC) provide a multidimensional framework for conceptualizing and measuring individual differences in musical preferences.

Moreover, the results from Rentfrow, Goldberg, and Levitin (2011) indicated that the music-preference dimensions were orthogonal, meaning that preferences for each dimension were independent of preferences for the other dimensions. Although it may appear on the surface that some of the preference factors are opposites (e.g., Mellow and Intense), the results from the factor analyses indicate 
otherwise. Furthermore, the orthogonality of the factors converges with anecdotal and empirical evidence that people use different styles of music to satisfy different needs (North \& Hargreaves, 1996, 1998). For example, someone might choose to listen to Mellow or Unpretentious music to unwind, Sophisticated music to create an ambience for dinner parties, Intense music for aerobic workouts, and Contemporary music for getting ready for a night on the town. Thus, preferences for one music dimension are independent of preferences for another.

The results from the Rentfrow, Goldberg, and Levitin (2011) studies replicated findings from previous research by providing strong evidence for five robust music-preference dimensions, and also clarified past research on music-genre preferences by identifying some of the properties that are common to pieces of music on the same dimension. The findings also suggested that the structure of musical preferences is not dependent entirely upon preferences for music genres, because several musical pieces from the same genre had their primary loadings on different factors. Furthermore, results from hierarchical multiple regression analyses suggested that the attributes of a piece of music predicted its location within the multidimensional MUSIC space over and above its genre classification. Thus, it would appear that the structure of musical preferences is influenced more by individuals' degree of liking for configurations of certain auditory and psychological attributes (e.g., inspiring and dynamic, distorted and aggressive) than by the social connotations of music genres (e.g., worldly, rebellious).

Rentfrow, Goldberg, and Levitin (2011) examined preferences for audio excerpts taken from a variety of musical genres, so it is difficult to know for sure the extent to which attributes were the main force underlying musical preferences. If musical preferences are based on liking for certain combinations of musical attributes rather than the social or other extramusical connotations associated with a particular genre, then a logical hypothesis to follow is that the MUSIC factors should emerge in a heterogeneous selection of musical pieces taken from a single genre. If, on the other hand, preferences are based on the degree to which individuals are attracted to the social-cognitive image associated with a style of music, then we should expect to find a single factor that reflects individual differences in preferences for that genre. The present research was designed to test this hypothesis.

Rentfrow, Goldberg, and Levitin (2011) coded songs on sound-related and psychological attributes. However, most of the sound-related attributes examined were quite broad (e.g., instrumental, loud) and there are other potentially important auditory parameters that could shape preferences. For instance, there are individual differences in timbre preferences (Williams, 1996), so it would be informative to code musical pieces for different instrumental families (e.g., strings, brass, woodwinds, synthesizers, etc.) to gain even more precise information about the nature of the preference factors. Furthermore, most of the psychological attributes examined pertained mainly to affect (e.g., aggressive, sad), but there is evidence that the energy level and perceived complexity of music may also contribute to preferences (e.g., Berlyne, 1971; North \& Hargreaves, 1995, 1996). Thus, to deepen our understanding of the properties that define and differentiate the MUSIC factors, the present research was also designed to examine a broad and diverse array of musical attributes.

\section{Overview of the Present Research}

The overarching question guiding this research program is: What are the determinants of musical preferences? Past work suggests that preferences are influenced by individuals' degree of liking for particular combinations of musical attributes as opposed to social connotations, but a systematic and rigorous investigation of this hypothesis has not yet been conducted. The present research was designed to build on that work by examining a broader set of musical attributes and investigating the structure of musical preferences within genres. Thus, the goal was to develop a deeper and more nuanced understanding of the factors underlying musical preferences.

Using multiple pieces of music, methods, and samples, three studies were conducted to achieve our research goals. Study 1 was designed to replicate the five-factor music-preference model reported in Rentfrow, Goldberg, and Levitin (2011) and to extend that work by investigating a larger set of auditory and psychological attributes. Specifically, preferences for 50 audio excerpts of musical pieces from 21 different music genres were assessed, and the pieces were coded on several auditory and psychological attributes. Studies 2 and 3 were designed to examine the structure of preferences for pieces of music within genres. Specifically, preferences for various jazz musical pieces were assessed in Study 2 and preferences for various rock pieces were assessed in Study 3.

\section{Study 1: The Structure of Preferences for Music from Different Genres}

Study 1 was designed to test whether the MUSIC preference model would replicate in a large and representative sample of Internet users, as opposed to music fans. Evidence of replication would provide further 
support for the multidimensional MUSIC preference model. Furthermore, to obtain a broader and more complete assessment of the properties characterizing the MUSIC factors, Study 1 was also designed to expand the set of auditory and psychological attributes previously examined. Examination of a larger set of attributes will provide a more nuanced and finely grained representation of the MUSIC factors.

\section{METHOD}

Participants. We were interested in the musical preferences of average music listeners, as opposed to trained musicians, and wanted to obtain such data for a representative sample of listeners as opposed to a sample of music fans or university students, which are the populations typically studied in musical preference research. We therefore recruited participants over the Internet via the online social networking website Facebook (http://www.facebook. com), using an application called "My Personality," which allows users to complete various psychological surveys. When users agree to use the "My Personality" application, they are asked for consent to use their responses to the surveys for research purposes.

The present study was conducted during the autumn of 2010. At that time, there were approximately 200,000 Facebook users who had used the "My Personality" application in the month prior to launching the survey. Of those users, 1,057 volunteered to participate in a study about musical preferences. Of those who indicated, $382(40 \%)$ were male and $585(60 \%)$ were female. The sample ranged in age from 18 to 60 and comprised mostly young adults, with mean age $=26.41(S D=9.23)$ and median age $=23$.

Procedure. Participants were invited to complete the musical preference measure in exchange for feedback about their preferences. The instructions indicated that completing the survey would require participants to listen to the pieces using speakers or headphones. Participants were then presented with each excerpt and asked to report their degree of preference for each one. Participants were able to play the excerpt multiple times.

Musical preference stimuli. One of the objectives of this study was to test the robustness of the MUSIC model (Rentfrow, Goldberg, \& Levitin, 2011). We did this using a subset of the pieces used in Study 2 of Rentfrow, Goldberg, and Levitin (2011). Specifically, excerpts of 50 musical pieces from 21 music genres and subgenres were selected. The excerpts were from pieces of real music, as opposed to music manufactured for an experiment, because real music is the type of music people are most likely to encounter in their daily lives, thus enhancing the ecological validity and generalizability of the research. To control for possible memory effects on preferences, we employed excerpts of commercially unreleased musical pieces obtained from Getty Images, a commercial service that provides photographs, films, and music for the advertising and media industries. All materials are of professional-grade in terms of the quality of recording, production, and composition (indeed, they pass through many of the same filters and levels of evaluation that commercially released recordings do). For details of the procedure used to select pieces from Getty Images, see Study 2 in Rentfrow, Goldberg, and Levitin (2011).

Each excerpt was approximately $15 \mathrm{~s}$ long. To avoid order effects, the excerpts were presented randomly for each participant. Participants were asked to indicate their degree of liking for each excerpt using a nine-point rating scale with endpoints at 1 (extremely dislike) and 9 (extremely like). The 50 pieces administered are listed in Table 1. The clips are available from the authors on request.

Musical attributes. Another objective of this project was to examine a broad array of musical attributes. A multi-step procedure was used to select attributes to add to the set of 14 (seven psychological and seven soundrelated attributes) investigated previously in Rentfrow, Goldberg, and Levitin (2011). In the first step, two experts independently generated lists of adjectives that could be used to describe psychological characteristics of music. Next, the two lists were compared and the experts agreed on a preliminary set of 100 psychological attributes. In the third step, 10 people were presented with the 100 adjectives and asked to indicate the extent to which each adjective could be useful in describing a piece of music, using a rating scale with endpoints at 1 (very useless) and 5 (very useful). Finally, adjectives that were given ratings $\geq 4$ by at least six of the raters were retained. This multistep procedure resulted in 29 new psychological attributes to add to the set of seven psychological attributes examined in Rentfrow, Goldberg, and Levitin (2011). The attributes can be grouped into four general categories: positive affect (i.e., amusing, animated, dreamy, enthusiastic, fun, happy, joyful, merry, sensual, strong, warm), negative affect (abrasive, angry, depressing, intense, tense), energy level (calming, danceable, forceful, gentle, lively, manic, mellow, party music, thrilling), and perceived complexity (deep, reflective, sophisticated, thoughtful).

To broaden the set of sound-related attributes, one expert independently generated a list of descriptors in terms of general instrumental timbres. That list was then 
reviewed and independently evaluated by a second expert, who added and deleted items from the original list. This resulted in a set of seven new attributes to add to the set of seven examined in Rentfrow, Goldberg, and Levitin (2011). The new attributes were: brass, heavy bass, piano, raspy voice, synthesizer, woodwind, and yelling voice.

Forty judges, with no formal music training, independently rated the 50 musical excerpts. To reduce the impact of fatigue and order effects, the judges were divided into four groups and coded 25 excerpts on 25 attributes; no judge rated all of the excerpts or attributes (mean number of judges per excerpt $=10$; range: $8-11$ ). Judges were unaware of the purpose of the study and were simply instructed to listen to each excerpt in its entirety, then to rate it on each of the musical attributes, using a 9-point scale with endpoints at 1 (extremely uncharacteristic) and 9 (extremely characteristic). Judges were given no specific instructions about what information they should use to make their judgments.

To assess the degree of attribute agreement between the groups of judges, we computed the mean Cronbach alpha for each attribute across each group of judges. Analyses of interjudge agreement across all the excerpts revealed high attribute agreement for the sound-related attributes ( $M$ alpha $=.88)$, with the highest agreement for instrumental $(M$ alpha $=.97)$ and the lowest agreement for distorted $(M$ alpha $=.73)$. Attribute agreement was also high for the psychologically oriented attributes $(M$ alpha $=.83)$, with the highest agreement for abrasive $(M$ alpha $=.94)$ and the lowest agreement for inspiring $(M$ alpha $=.60)$.

\section{RESULTS AND DISCUSSION}

Factor analysis. Multiple criteria were used to decide how many factors to retain: parallel analyses of Monte Carlo simulations (i.e., factor analyses of random data with the same number of variables as musical pieces), replicability across factor-extraction methods, and factor interpretability. Principal components analysis (PCA) with varimax rotation yielded a substantial first factor that accounted for $24 \%$ of the variance, reflecting individual differences in general preferences for music. Parallel analysis of random data suggested that the first six eigenvalues were significantly greater than chance in accounting for variability in the data. Examination of the scree plot suggested an "elbow" at roughly six factors. Successive PCAs with varimax rotation were then performed for one-factor through six-factor solutions. In the six-factor solution, the sixth factor was comparatively small (accounting for 3\% of the variance) and had many items with large secondary loadings. Altogether these analyses suggested that we retain no more than five broad music-preference factors.
To determine whether the factors were invariant across methods, we examined the convergence between orthogonally rotated factor scores from PCA, principleaxis (PA), and maximum-likelihood (ML) extraction procedures. Specifically, PCAs, PAs, and MLs were performed for one- through five-factor solutions; the factor scores for each solution were then intercorrelated. The results revealed very high convergence across the three extraction methods, with correlations averaging above .99 between the PCA and PA factors, .99 between the PCA- and ML factors, and above 99 between the PA and ML factors. These results indicate that the same solutions would be obtained regardless of the particular factor-extraction method that was used. As PCAs yield exact and perfectly orthogonal factor scores, solutions derived from PCAs are reported in this article.

The final five-factor solution was consistent with our expectations and clearly resembled the MUSIC model. As can be seen in Table 1, the Mellow factor comprised excerpts from the easy listening, R \& B/soul, soft rock, adult contemporary, and electronica genres. The Unpretentious factor comprised musical excerpts from the country, bluegrass, country-rock, and rock'n roll genres. Sophisticated comprised excerpts from the avant-garde classical, classical, Latin, traditional jazz, world beat, electronica, and adult contemporary genres. The Intense music-preference factor comprised excerpts from the punk, classic rock, and heavy metal genres. And finally, the Contemporary music-preference dimension comprised excerpts from the rap, R \& B/soul, Europop, and electronica genres.

Attribute analysis. The second aim of this study was to examine the musical attributes associated with the MUSIC factors. Using the song excerpts as the unit of analysis, we correlated the factor loadings of each excerpt on each MUSIC factor (shown in Table 1) with the mean of the judges' ratings of the sound-related and psychological attributes of the excerpts. These analyses enable us to identify which attributes define and differentiate the MUSIC factors.

As can be seen in Table 2, the patterns of correlations between the MUSIC factors and the attributes varied considerably by factor. The coefficients in the first data column show the results for the Mellow factor. In terms of the sound characteristics, the excerpts with high loadings on the Mellow factor were perceived as slow, quiet, not distorted, and acoustic. In terms of psychological characteristics, there were mixed patterns of relationships with the positive affect attributes, such that the excerpts were perceived as dreamy, romantic, warm, sensual, and inspiring, but not animated, enthusiastic, amusing, or fun; the Mellow pieces were generally low 
TABLE 1. Five Varimax-Rotated Principal Components Derived from 50 Music Excerpts from Different Genres.

\begin{tabular}{|c|c|c|c|c|c|c|c|}
\hline \multirow[b]{2}{*}{ Artist } & \multirow[b]{2}{*}{ Piece } & \multirow[b]{2}{*}{ Genre } & \multicolumn{5}{|c|}{ Principal component } \\
\hline & & & M & $\mathrm{U}$ & S & I & $\mathrm{C}$ \\
\hline The O'Neill Brothers & Through the Years & Smooth Jazz & .74 & .17 & .22 & -.09 & .13 \\
\hline Frank Josephs & Mountain Trek & $\mathrm{R} \& \mathrm{~B} /$ soul & .72 & .18 & .17 & -.05 & .14 \\
\hline Human Signals & Birth & Soft rock & .67 & .08 & .27 & -.03 & .16 \\
\hline Bruce Smith & Children of Spring & Adult contemporary & .65 & .14 & .38 & -.05 & .01 \\
\hline Walter Rodriguez & Safety & Electronica & .59 & .01 & .13 & .02 & .45 \\
\hline Language Room & She Walks & Soft rock & .54 & .24 & .06 & .19 & .08 \\
\hline Ali Handal & Sweet Scene & Soft rock & .52 & .38 & .31 & .03 & .01 \\
\hline Taryn Murphy & Love Along The Way & Soft rock & .50 & .43 & -.02 & .11 & .16 \\
\hline Kush & Sweet 5 & Electronica & .50 & .02 & .49 & -.06 & .29 \\
\hline James E. Burns & I’m Already Over You & New country & .30 & .79 & .08 & -.04 & .03 \\
\hline Babe Gurr & Newsreel Paranoia & Bluegrass & .13 & .76 & .18 & -.04 & .03 \\
\hline Bob Delevante & Penny Black & New country & .25 & .75 & .13 & .01 & .05 \\
\hline Five Foot Nine & Lana Marie & Country-rock & .34 & .71 & .10 & -.05 & .03 \\
\hline Curtis & Carrots \& Grapes & Rock-n-roll & -.05 & .69 & .29 & .14 & .02 \\
\hline Anglea Motter & Mama I'm Afraid to go There & Bluegrass & -.11 & .65 & .35 & .14 & .06 \\
\hline Carey Sims & Praying for Time & Mainstream country & .47 & .65 & -.02 & .05 & .08 \\
\hline Hillbilly Hellcats & That's Not Rockabilly & Rock-n-roll & -.11 & .64 & .27 & .03 & -.02 \\
\hline Laura Hawthorne & Famous Right Where I Am & Mainstream country & .46 & .62 & -.12 & .01 & .10 \\
\hline Ljova & Seltzer, do I Drink Too Much? & Avant-garde classical & .04 & .11 & .82 & .06 & .07 \\
\hline Laurent Martin & Scriabin Etude Opus 65 No 3 & Avant-garde classical & .03 & .00 & .76 & .05 & -.02 \\
\hline Antonio Vivaldi & Concerto in $\mathrm{C}$ & Classical & .21 & .05 & .75 & .00 & -.06 \\
\hline Various Artists & La Trapera & Latin & -.01 & .19 & .75 & -.04 & .15 \\
\hline Bruce Smith & Sonata A Major & Classical & .31 & .08 & .70 & -.04 & -.03 \\
\hline DNA & La Wally & Classical & .18 & .06 & .69 & .07 & .00 \\
\hline Paul Serrato \& Co. & Who are You? & Traditional jazz & .07 & .10 & .68 & .02 & .25 \\
\hline Moh Alileche & North Africa's Destiny & World beat & .06 & .20 & .67 & .01 & .07 \\
\hline Daniel Nahmod & I Was Wrong & Traditional jazz & .34 & .13 & .64 & -.04 & .23 \\
\hline Lisa McCormick & Fernando Esta Feliz & Latin & .06 & .27 & .63 & -.03 & .25 \\
\hline $\mathrm{AB}+$ & Recess & Electronica & .40 & -.01 & .54 & -.04 & .34 \\
\hline Lisa McCormick & Let's Love & Adult contemporary & .30 & .29 & .51 & .02 & .16 \\
\hline Bankrupt & Face the Failure & Punk & -.05 & .00 & -.01 & .85 & -.02 \\
\hline Squint & Michigan & Punk & -.04 & .03 & -.02 & .83 & -.06 \\
\hline $\begin{array}{l}\text { Straight Outta Junior } \\
\text { High }\end{array}$ & Over Now & Punk & -.06 & .11 & .05 & .82 & .00 \\
\hline Exit 303 & Falling Down 2 & Classic rock & .15 & .05 & -.01 & .82 & -.01 \\
\hline $\begin{array}{l}\text { Five Finger Death } \\
\text { Punch }\end{array}$ & Death Before Dishonor & Heavy metal & .08 & -.12 & -.02 & .80 & -.01 \\
\hline The Tomatoes & Johnny Fly & Classic rock & -.06 & .14 & .04 & .79 & .01 \\
\hline Cougars & Dick Dater & Classic rock & -.15 & .21 & .08 & .76 & .08 \\
\hline The Stand In & Frequency of a Heartbeat & Punk & .10 & .09 & .01 & .75 & .07 \\
\hline $\begin{array}{l}\text { Five Finger Death } \\
\text { Punch }\end{array}$ & White Knuckles & Heavy metal & -.11 & -.12 & -.05 & .74 & .01 \\
\hline Dawn Over Zero & Out of Lies & Heavy metal & .14 & -.10 & -.03 & .72 & .10 \\
\hline Sammy Smash & Get the Party Started & Rap & -.02 & .13 & -.09 & .06 & .76 \\
\hline
\end{tabular}


TABLE 1. Continued.

\begin{tabular}{|c|c|c|c|c|c|c|c|}
\hline \multirow[b]{2}{*}{ Artist } & \multirow[b]{2}{*}{ Piece } & \multirow[b]{2}{*}{ Genre } & \multicolumn{5}{|c|}{ Principal component } \\
\hline & & & M & $\mathrm{U}$ & $S$ & I & $\mathrm{C}$ \\
\hline Mykill Miers & Immaculate & Rap & .08 & .03 & .10 & .08 & .75 \\
\hline Ciph & Brooklyn Swagger & Rap & -.10 & .15 & -.05 & .07 & .75 \\
\hline Preston Middleton & Latin 4 & R\&B/soul & .16 & .04 & .23 & -.01 & .73 \\
\hline Robert LaRow & Sexy & Europop & .05 & .13 & .13 & -.06 & .72 \\
\hline Leo the Lionheart & Electro & Electronica & .33 & -.10 & .20 & -.04 & .69 \\
\hline DJ Come of Age & Thankful & $\mathrm{R} \& \mathrm{~B} /$ soul & .23 & .22 & .03 & -.11 & .62 \\
\hline Magic Dingus Box & The Way It Goes & Electronica & .35 & -.13 & .18 & .04 & .52 \\
\hline The Cruxshadows & Go Away & Europop & .30 & -.21 & .25 & .08 & .50 \\
\hline Benjamin Chan & MATRIX & Electronica & .04 & -.23 & .15 & .34 & .46 \\
\hline
\end{tabular}

Note: $\mathrm{M}=$ Mellow; $\mathrm{U}=$ Unpretentious; $\mathrm{S}=$ Sophisticated; $\mathrm{I}=$ Intense; $\mathrm{C}=$ Contemporary. Each piece's largest factor loading is in italics. Factor loadings $>|.40|$ are in bold typeface.

in negative affect, with negative relationships for abrasive, tense, intense, angry, and aggressive, and a positive correlation with sad; a strong and consistent pattern of correlations appeared with the energy attributes, indicating that the excerpts on this factor were perceived as mellow, gentle, calming, and relaxing, and not lively, forceful, manic, thrilling, party music, or danceable; and the pieces were generally considered cerebral, with positive relationships with reflective, thoughtful, deep, sophisticated, and intelligent.

The correlations between the Unpretentious factor and attributes can be seen in the second data column of Table 2. In terms of auditory characteristics, the excerpts with high loadings on the Unpretentious factor were perceived as lacking heavy bass and distortion, and having primarily acoustic instruments and vocals. In terms of the psychological characteristics, the pieces on this dimension were perceived as possessing some degree of positive affect, with positive relationships with amusing, fun, warm, but a negative relationship with strong; the excerpts on this factor were perceived as being low in negative affect, with negative relationships with tense, intense, angry, abrasive, and aggressive; Unpretentious pieces were also perceived as low in energy, with negative links to the thrilling, manic, and forceful attributes; and the pieces on this dimension are not generally perceived as cerebral, with negative correlations with complex and sophisticated.

As can be seen in the third data column of Table 2, there were several associations between the Sophisticated factor and the attributes. The pieces with high loadings on the Sophisticated factor were perceived as quiet, clear sounding, slow, and lacking heavy bass or percussion; the Sophisticated pieces were also perceived as having sounds produced by acoustic instruments, pianos, brass instruments, and not having vocals. In terms of psychological characteristics, the pieces were associated with several of the positive affect attributes, including joyful, inspiring, merry, romantic, warm, dreamy, sensual, and amusing; the excerpts were perceived as lacking negative affect, as indicated by negative relationships with abrasive, angry, aggressive, and depressing; pieces on this factor were also perceived as having a somewhat low energy level, as indicated by positive links with relaxing, calming, gentle, and mellow, and negative associations with party music, forceful, danceable, and manic; the Sophisticated pieces were generally perceived as being cerebral, with strong positive correlations with sophisticated, intelligent, and thoughtful.

The fourth data column in Table 2 shows the correlations between the Intense factor and the attributes. In terms of auditory characteristics, the excerpts with high factor loadings on this factor were perceived as loud, distorted, fast, percussive, dense, and having heavy bass; the vocalists in the excerpts were perceived as yelling and having raspy voices, and the instruments were predominantly electric. In terms of the psychological characteristics, the pieces were perceived as lacking many aspects of positive affect, with strong negative correlations with warm, romantic, sensual, dreamy, joyful, merry, inspiring, and happy, and positive links with strong, enthusiastic, and animated; the pieces were perceived as possessing considerable negative affect, with strong positive correlations with angry, abrasive, aggressive, intense, and tense; the excerpts on this factor were also perceived as being very high energy, as indicated by the strong positive correlations with forceful, manic, thrilling, party music, and lively, and negative correlations with gentle, mellow, calming, and relaxing; the Intense pieces were not perceived as 
TABLE 2. Correlations Between the Mixed-Genre MUSIC Factor Loadings in Study 1 and Musical Attributes.

\begin{tabular}{|c|c|c|c|c|c|}
\hline Attributes & M & $\mathrm{U}$ & $\mathrm{S}$ & I & $\mathrm{C}$ \\
\hline \multicolumn{6}{|l|}{ Sound-related } \\
\hline \multicolumn{6}{|l|}{ Auditory features } \\
\hline Dense $^{\mathrm{a}}$ & -.18 & -.06 & -.23 & $.34^{*}$ & -.03 \\
\hline Distorted $^{\mathrm{a}}$ & $-.29^{\star}$ & $-.39^{\star}$ & $-.32^{\star}$ & $.60^{*}$ & -.06 \\
\hline Fast $^{\mathrm{a}}$ & $-.52^{\star}$ & -.21 & $-.29^{\star}$ & $.57^{\star}$ & -.07 \\
\hline Heavy bass & $-.42^{\star}$ & $-.49^{*}$ & $-.37^{\star}$ & $.30^{*}$ & $.61^{*}$ \\
\hline Loud $^{\text {a }}$ & $-.58^{\star}$ & -.19 & $-.44^{\star}$ & $.79^{*}$ & -.21 \\
\hline Percussive $^{a}$ & -.25 & -.13 & $-.44^{\star}$ & $.53^{*}$ & .00 \\
\hline \multicolumn{6}{|l|}{ Instruments } \\
\hline Brass & .10 & -.11 & $.34^{\star}$ & -.18 & .06 \\
\hline Electric $^{\mathrm{a}}$ & -.23 & $-.40^{*}$ & $-.57^{\star}$ & $.38^{\star}$ & $.52^{*}$ \\
\hline Instrumental $^{\mathrm{a}}$ & .20 & $-.47^{\star}$ & $.28^{\star}$ & .09 & -.01 \\
\hline Piano & .22 & -.18 & $.52^{\star}$ & $-.32^{\star}$ & -.01 \\
\hline Raspy voice & $-.32^{\star}$ & -.03 & $-.33^{\star}$ & $.49^{*}$ & -.18 \\
\hline Synthesizer & .20 & $-.39^{*}$ & -.20 & -.25 & $.71^{\star}$ \\
\hline Woodwind & .20 & -.13 & .15 & -.15 & -.01 \\
\hline Yelling voice & $-.29^{\star}$ & -.16 & $-.38^{\star}$ & $.51^{\star}$ & -.09 \\
\hline \multicolumn{6}{|l|}{ Psychological } \\
\hline \multicolumn{6}{|l|}{ Positive affect } \\
\hline Amusing & $-.52^{\star}$ & $.36^{*}$ & $.27^{\star}$ & -.15 & -.06 \\
\hline Animated & $-.74^{\star}$ & -.21 & .09 & $.33^{*}$ & .07 \\
\hline Dreamy & $.74^{\star}$ & -.10 & $.39^{*}$ & $-.54^{*}$ & .09 \\
\hline Enthusiastic & $-.64^{\star}$ & -.11 & .01 & $.40^{*}$ & -.04 \\
\hline Fun & $-.35^{\star}$ & $.29^{*}$ & .04 & -.06 & .10 \\
\hline Happy & -.04 & .18 & .24 & $-.34^{*}$ & .18 \\
\hline Inspiring $^{\mathrm{a}}$ & $.34^{\star}$ & -.02 & $.59^{*}$ & $-.37^{\star}$ & $-.27^{\star}$ \\
\hline Joyful & .16 & .04 & $.61^{\star}$ & $-.46^{*}$ & -.05 \\
\hline Merry & .05 & .06 & $.57^{\star}$ & $-.40^{*}$ & -.02 \\
\hline Romantic $^{\mathrm{a}}$ & $.60^{*}$ & .04 & $.55^{\star}$ & $-.57^{\star}$ & -.08 \\
\hline Sensual & $.33^{*}$ & -.07 & $.33^{\star}$ & $-.57^{\star}$ & $.43^{*}$ \\
\hline Strong & $-.73^{\star}$ & $-.34^{\star}$ & -.17 & $.76^{*}$ & -.17 \\
\hline Warm & $.53^{*}$ & $.28^{\star}$ & $.54^{*}$ & $-.65^{\star}$ & -.09 \\
\hline \multicolumn{6}{|l|}{ Negative affect } \\
\hline Abrasive & $-.69^{\star}$ & $-.31^{\star}$ & $-.50^{\star}$ & $.79^{\star}$ & -.02 \\
\hline Aggressive $^{\mathrm{a}}$ & $-.62^{\star}$ & $-.29^{\star}$ & $-.41^{\star}$ & $.78^{*}$ & -.14 \\
\hline Angry & $-.64^{\star}$ & $-.34^{\star}$ & $-.42^{\star}$ & $.80^{\star}$ & -.12 \\
\hline Depressing & .22 & .04 & $-.37^{\star}$ & .26 & $-.28^{\star}$ \\
\hline Intense & $-.68^{\star}$ & $-.40^{*}$ & -.24 & $.76^{\star}$ & -.14 \\
\hline $\mathrm{Sad}^{\mathrm{a}}$ & $.35^{\star}$ & .23 & .17 & -.21 & $-.26^{*}$ \\
\hline Tense & $-.68^{\star}$ & $-.42^{\star}$ & -.26 & $.75^{\star}$ & -.09 \\
\hline \multicolumn{6}{|l|}{ Energy } \\
\hline Calming & $.80^{*}$ & .12 & $.39^{*}$ & $-.67^{\star}$ & .03 \\
\hline Danceable & $-.37^{\star}$ & .05 & $-.35^{\star}$ & .08 & $.43^{*}$ \\
\hline
\end{tabular}


TABLE 2. Continued.

\begin{tabular}{|c|c|c|c|c|c|}
\hline Attributes & M & $\mathrm{U}$ & S & I & $\mathrm{C}$ \\
\hline Forceful & $-.67^{\star}$ & $-.42^{*}$ & $-.36^{*}$ & $.88^{*}$ & -.15 \\
\hline Gentle & $.81^{\star}$ & .19 & $.36^{\star}$ & $-.70^{*}$ & .02 \\
\hline Lively & $-.69^{\star}$ & -.12 & -.07 & $.43^{\star}$ & .02 \\
\hline Manic & $-.65^{\star}$ & $-.45^{\star}$ & $-.35^{\star}$ & $.81^{\star}$ & -.06 \\
\hline Mellow & $.82^{\star}$ & .15 & $.31^{\star}$ & $-.69^{*}$ & .11 \\
\hline Party music & $-.55^{\star}$ & -.20 & $-.49^{*}$ & $.44^{*}$ & $.41^{\star}$ \\
\hline Relaxing $^{\mathrm{a}}$ & $.65^{\star}$ & .06 & $.53^{\star}$ & $-.61^{*}$ & -.05 \\
\hline Thrilling & $-.64^{\star}$ & $-.46^{*}$ & -.13 & $.66^{*}$ & -.03 \\
\hline \multicolumn{6}{|l|}{ Cerebral } \\
\hline Complex $^{\mathrm{a}}$ & -.19 & $-.35^{\star}$ & .20 & .18 & -.09 \\
\hline Deep & $.49^{*}$ & -.02 & .24 & -.18 & -.22 \\
\hline Intelligent $^{\mathrm{a}}$ & $.37^{\star}$ & -.10 & $.63^{*}$ & $-.42^{*}$ & -.16 \\
\hline Reflective & $.78^{\star}$ & .24 & .21 & $-.53^{\star}$ & -.12 \\
\hline Sophisticated & $.43^{*}$ & $-.27^{\star}$ & $.82^{\star}$ & $-.52^{\star}$ & -.05 \\
\hline Thoughtful & $.63^{*}$ & .22 & $.47^{\star}$ & $-.53^{*}$ & $-.26^{*}$ \\
\hline
\end{tabular}

Note: Cell entries are correlations between the factor loadings (standardized using Fisher's $r$-to- $z$ transformation) of the excerpts used in Study 1 and the mean attribute ratings of the excerpts. $\mathrm{M}=$ Mellow; $\mathrm{U}=$ Unpretentious; $\mathrm{S}=$ Sophisticated; $\mathrm{I}=$ Intense; $\mathrm{C}=$ Contemporary. ${ }^{\mathrm{a}}=$ Attribute was assessed in Rentfrow, Goldberg, and Levitin $(2011) . N=50 .{ }^{*} p<.05$.

being cerebral, with negative correlations with reflective, thoughtful, sophisticated, and intelligent.

Finally, as can be seen in the fifth data column of Table 2 , the excerpts on the Contemporary factor were associated with a few attributes. In terms of auditory characteristics, the pieces with high loadings on this factor had heavy bass sounds, synthetic sounds, and electric instruments. In terms of psychological characteristics, the excerpts on this factor were perceived as sensual but not inspiring; they were perceived as low in negative affect, with negative correlations with depressing and sad; excerpts on this factor were perceived as energetic, as indicated by positive links with danceable and party music; and the pieces were not perceived as especially cerebral, as indicated by a negative relationship with thoughtful.

The patterns of correlations between the MUSIC factors and attributes are remarkably consistent with those reported previously, suggesting that the model is very robust. To formally test the extent to which the MUSIC factors observed in the current study possess auditory and psychological properties similar to those reported in Rentfrow, Goldberg, and Levitin (2011), we examined the patterns of correlations between the MUSIC factors and attributes observed in the current study (and reported in Table 2) and those reported in Table 4 of Rentfrow, Goldberg, and Levitin. Specifically, we used Fisher's $r$-to- $z$ transformation to standardize the correlation coefficients of the 14 attributes that were examined in both studies. We then computed the column-vector correlations for each of the MUSIC factors. The analyses revealed very high convergence for all five factors (column-vector correlations $=.96, .85$, $.92, .97$, and .81, for M, U, S, I, and C, respectively). These results clearly indicate that the properties of MUSIC factors reported in the present study are robust and strongly consistent with the properties of the model reported in previous research.

Summary. The results from the present study are consistent with previous research on the MUSIC model (Rentfrow, Goldberg, \& Levitin, 2011). Factor analyses of the music-preference data revealed five robust and interpretable dimensions with musical pieces from different genres. The patterns of correlations between the MUSIC factors and attributes were also highly consistent with those reported previously. Overall, the findings from this study indicate that the MUSIC model is robust and raise the possibility that attributes (rather than genre) could be the driving force behind the music-preference dimensions. If the music-preference space is defined by particular musical characteristics, as opposed to genre classification, then it is reasonable to expect factors resembling MUSIC should emerge among preferences for pieces of music from the same genre. 


\section{Study 2: The Structure of Preferences for Jazz Music}

The aim of this study was to investigate the hypothesis that the MUSIC model reflects individual differences in preferences for particular combinations of musical characteristics, even within a genre. Previous research suggests that the MUSIC factors are defined and differentiated by certain musical attributes that account for significant proportions of variance in preferences over and above genre classification (Rentfrow, Goldberg, \& Levitin, 2011). Those findings suggest that the preference factors are driven by affective reactions to certain musical attributes in addition to preferences for genres or their social connotations. However, that work included pieces of music from a variety of music genres and, as we showed above, attributes are not distributed evenly across genres, so support for the hypothesis is only indirect because genres and attributes have been confounded in previous studies. The strongest test, therefore, of this hypothesis would be if the five MUSIC factors could be replicated solely using musical excerpts from a single genre.

The present study was designed to test this hypothesis directly by examining individual differences in the structure of preferences for pieces of music from within the same genre. If preferences are indeed shaped by affective reactions to particular musical attributes, we should expect to find multiple preference factors that are defined by certain attributes. Furthermore, if the MUSIC model is robust and captures the most basic dimensions of musical preferences, we should expect to find factors that resemble MUSIC. On the other hand, if preferences are determined by preferences for the social connotations associated with a genre, instead of musical attributes, we should expect a single factor that reflects individual differences in preferences for that genre.

Which genre should be used to test this hypothesis? The ideal genre would be one that spans a variety of musical styles and also has strong social connotations. Jazz is a broad and diverse music genre, and comprises several subgenres, from Dixieland, swing, and bebop, to modal, free, and fusion. There are also clearly defined social connotations, or stereotypes, associated with jazz music fans: jazz listeners are believed to be creative, laidback, and introspective (Rentfrow \& Gosling, 2007; Rentfrow et al., 2009). Given that jazz is a rich genre with strong social connotations, it is an ideal genre for addressing the aims of the current study.

\section{METHOD}

Participants. We were interested in the musical preferences of music listeners and wanted to obtain such data for a representative sample. As in Study 1, we collected musical preference data from a large and diverse sample of Internet users. Despite the advantages of Internet samples, it is difficult to know anything about the conditions in which participants completed the measures, whether they listened to each clip in its entirety, or whether they even listened to the clips at all. Therefore, we also collected data from an undergraduate student sample, where we could exert more control over the assessment conditions. This allowed us to evaluate the reliability and generalizability of the results.

The Internet sample was recruited using the same methods used in Study 1. In the autumn of 2010, users of the "My Personality" Facebook application were invited to participate in a study concerned with preferences for jazz music. Of the active users, 913 volunteered to complete the jazz music-preference measure. Of those who indicated, $345(40 \%)$ were male and $511(60 \%)$ were female. The sample ranged in age from 14 to 68 and comprised mostly young adults, with mean age $=23.87$ and median age $=21(S D=9.11)$.

The undergraduate student sample comprised students at the University of Texas at Austin enrolled in an introductory psychology course during the 2010 Fall semester. Students were invited to complete a musical preference measure. There were 408 students who chose to participate. Of those who indicated, $142(36 \%)$ were male and 251 (64\%) were female. Information about participants' age was not collected. However, the median age of participants enrolled in introductory psychology in previous semesters was 18 , and the demographic composition of the current sample was not noticeably different from those of previous semesters (see Rentfrow, Goldberg, \& Levitin, 2011; Study 3), so it is reasonable to expect the median age of the sample to also be 18 .

Procedure. Participants in the Internet sample were invited to complete the musical preference measure in exchange for feedback about their preferences. The instructions indicated that completing the survey would require participants to listen to the pieces using speakers or headphones. Participants were then presented with 50 excerpts and asked to report their degree of preference for each one. Participants were able to play the excerpt multiple times.

As part of the curriculum for the introductory psychology course, surveys, questionnaires, and exercises that pertained to the lecture topics were periodically administered to students. A survey about musical preferences was administered as part of the lecture unit on personality and individual differences. Students were invited to participate in a study of musical preferences, which involved listening to 25 music excerpts and reporting their degree of liking for each one. All the musical excerpts were played entirely and only once. 
Musical preference stimuli. A multistep procedure was used to select jazz music excerpts. First, one expert judge with an extensive jazz music library searched his collection for a broad range of jazz pieces. The task was to identify exemplary pieces of jazz that spanned as much of the jazz music space as possible and to then nominate a set of pieces to use as stimuli in the study. Next, a second judge with extensive knowledge of jazz music examined the nominated pieces and removed pieces that were redundant or added pieces for jazz styles that were not sufficiently represented. Finally, the revised set of pieces was circulated among a group of three experts, including the two judges from steps 1 and 2, to ensure that as much of the jazz space was covered as possible. This multistep procedure resulted in a set of 50 jazz music excerpts.

Participants in the Internet sample reported their degree of liking for each of the 50 excerpts using a 9-point rating scale, with endpoints at 1 (extremely dislike) and 9 (extremely like). Participants in the university sample reported their degree of liking for each of the 25 pieces using a 5-point rating scale with endpoints at 1 (extremely dislike) and 5 (extremely like). The 50 pieces administered to the Internet sample and the 25 pieces administered to the university sample are listed in Table 3. The clips are available from the authors on request.

Musical attributes. The jazz pieces were coded on the same 50 attributes using the same procedure as in Study 1.61 judges with no formal music training independently rated the 50 jazz excerpts; no judge rated all of the excerpts or attributes (mean number of judges per excerpt $=10$; range: 9-11). Analyses of interjudge agreement across all the excerpts revealed high attribute agreement (i.e., Cronbach's alpha) for the sound-related attributes $(M$ alpha $=.87)$, with the highest agreement for instrumental $(M$ alpha $=.98)$ and the lowest agreement for distorted $(M$ alpha $=.57)$. Attribute agreement was also high for the psychologically oriented attributes ( $M$ alpha $=.77)$, with the highest agreement for mellow ( $M$ alpha $=.91)$ and the lowest agreement for warm ( $M$ alpha $=.51)$.

\section{RESULTS AND DISCUSSION}

Factor analysis. Based on our a priori hypothesis that preferences are based on properties of the music and that the MUSIC model captures the most basic dimensions of musical preferences, we expected five music-preference factors to be extracted. For both the Internet and student samples, multiple criteria were used to determine the number of music-preference factors to retain. For the Internet sample, a PCA with varimax rotation of the 50 excerpts yielded a large first factor that accounted for $37 \%$ of the variance; parallel analysis of random data suggested that the first five eigenvalues were greater than chance; and the scree plot suggested an "elbow" at roughly five factors. For the university sample, a PCA with varimax rotation of the 25 excerpts yielded a large first factor that accounted for $34 \%$ of the variance; parallel analysis of random data suggested that the first five eigenvalues were greater than chance; and the scree plot suggested an "elbow" at roughly five factors. We next inspected the loadings for four, five, and six-factor models. The four-factor models yielded a structure with a fourth factor that was difficult to interpret; the five-factor model revealed five interpretable factors with few crossloading excerpts; and the six-factor model generated a comparatively small sixth factor composed of two to three musical excerpts with large secondary factor loadings. Based on these findings, we elected to retain the first five music-preference factors obtained in both samples.

For both the Internet and undergraduate samples, factor invariance across extraction methods revealed very high convergence across the PCA, PA, and ML extraction methods, with correlations averaging above .999 between the PCA and PA factors, .99 between the PCA and ML factors, and over .999 between the PA and ML factors. Comparisons of factor scores derived from PCAs with orthogonal and oblique rotations revealed high convergence across rotation methods, with correlations across the corresponding MUSIC factors averaging .97. These results indicate that the same solutions would be obtained regardless of the particular extraction or rotation method used. The five-factor solutions derived from the PCAs with varimax rotation are reported.

The five-factor solution that emerged in the Internet sample was highly consistent with our expectations and clearly resembled the MUSIC model. As can be seen in Table 3, there was a factor comprising excerpts of smooth jazz by artists such as Kenny $G$ and Norah Jones, which we interpreted as corresponding to the Mellow factor. There was a factor comprising excerpts of early jazz, blues, and jazz vocals music by artists such as Bessie Smith and Louis Armstrong, and resembled the Unpretentious factor. A third factor emerged that reflected the Sophisticated dimension, with pieces of bebop, modal, and fusion by artists including Charlie Parker, Pharaoh Sanders, and Bud Powell. A fourth factor comprising three excerpts with comparatively high loadings of jazz-fusion pieces by artists such as Jeff Beck and Stanley Clarke reflected the Intense dimension. And the fifth factor to emerge clearly resembled the Contemporary dimension, with excerpts of acid jazz and jazz rap pieces by artists such as St. Germain and Us3.

The five factors that emerged in the undergraduate student sample were very similar to the factors in the Internet sample. To empirically compare the two factor structures, we compared the patterns of factor loadings for 25 excerpts that were administered to both samples. Specifically, for the 


\begin{tabular}{|c|c|c|c|c|c|c|}
\hline \multirow[b]{2}{*}{ Artist } & \multirow[b]{2}{*}{ Piece } & \multicolumn{5}{|c|}{ Principal component } \\
\hline & & $\mathrm{M}$ & $\mathrm{U}$ & $S$ & I & $\mathrm{C}$ \\
\hline Kenny G & Forever In Love ${ }^{\mathrm{a}}$ & .84 & .07 & .09 & -.01 & .12 \\
\hline Mezzoforte & After Hours & .82 & .01 & .15 & .01 & .16 \\
\hline Earl Klugh & Long Ago \& Far Away ${ }^{a}$ & .81 & .11 & .09 & .08 & .18 \\
\hline Kenny G & Sister Rose & .79 & .06 & .19 & .02 & .12 \\
\hline Joe Sample & In All My Wildest Dreams ${ }^{a}$ & .72 & .12 & .12 & .02 & .30 \\
\hline Bob James & Angela & .72 & .12 & .16 & .03 & .31 \\
\hline Norah Jones & Come Away With $\mathrm{Me}^{\mathrm{a}}$ & .54 & .35 & -.04 & .05 & .25 \\
\hline Sade & Smooth Operator ${ }^{\mathrm{a}}$ & .54 & .17 & .01 & -.06 & .47 \\
\hline Bessie Smith & The St. Louis Blues ${ }^{\mathrm{a}}$ & -.06 & .78 & .18 & .00 & .05 \\
\hline Louis Armstrong & Gut Bucket Blues & .03 & .78 & .25 & .03 & .07 \\
\hline Billie Holiday & All Of Me & .09 & .76 & .25 & -.14 & .16 \\
\hline Cab Calloway \& his Orchestra & Minnie The Moocher & -.11 & .74 & .25 & -.02 & .15 \\
\hline Django Reinhardt & Daphne $^{\mathrm{a}}$ & .17 & .72 & .20 & .08 & .04 \\
\hline Joe Liggins \& his Honeydrippers & The Honeydripper ${ }^{\mathrm{a}}$ & .10 & .72 & .41 & .03 & .13 \\
\hline Ella Fitzgerald \& Louis Armstrong & Cheek To Cheek & .31 & .67 & .27 & -.11 & .19 \\
\hline Amos Easton (Bumble Bee Slim) & Ida Red & .06 & .67 & .14 & .07 & .34 \\
\hline Chet Atkins (\& Merle Travis) & Nine Pound Hammer ${ }^{\mathrm{a}}$ & .21 & .64 & .14 & .28 & .03 \\
\hline Jacques Montagne & Charmaine & .18 & .63 & .45 & .10 & .06 \\
\hline Paul Simon & Hobo's Blues & .25 & .61 & .18 & .21 & .04 \\
\hline Michael Civisca & Moonglow & .42 & .55 & .24 & -.10 & .09 \\
\hline Jazz Futures & Public Eye ${ }^{a}$ & .03 & .18 & .85 & .10 & .17 \\
\hline Pharoah Sanders & Origin $^{a}$ & .12 & .12 & .85 & .11 & .16 \\
\hline Pharoah Sanders & Moments Notice ${ }^{a}$ & .23 & .18 & .82 & .05 & .08 \\
\hline Jacques Loussier & Italian Concerto: Presto ${ }^{a}$ & .14 & .24 & .82 & .08 & .11 \\
\hline Cannonball "Julian" Adderley & What Is This Thing Called Love? ${ }^{a}$ & .14 & .32 & .82 & .00 & .08 \\
\hline Derrick Shezbie & Softly As In A Morning Sunrise ${ }^{\mathrm{a}}$ & .20 & .31 & .78 & -.01 & .18 \\
\hline Charlie Parker & Ko Ko & .11 & .29 & .78 & -.02 & .09 \\
\hline Joe Henderson & Junk Blues & -.04 & .15 & .74 & .16 & .14 \\
\hline Miles Davis & Directions I & -.08 & .11 & .73 & .22 & .15 \\
\hline Bud Powell & Tempus Fugit (Tempus Fugue-it) & .14 & .39 & .70 & .05 & .06 \\
\hline Gary Burton Quintet & Ictus/Syndrome & .28 & .14 & .69 & .08 & .14 \\
\hline Patrick Saussois \& Alma Sinti & Tune $\mathrm{Up}^{\mathrm{a}}$ & .23 & .40 & .62 & .13 & .15 \\
\hline Miles Davis & John McLaughlin ${ }^{a}$ & .06 & .20 & .58 & .41 & .19 \\
\hline Michael Franks & My Foolish Heart & .41 & .38 & .58 & -.10 & .06 \\
\hline Buddy Rich & The Nitty Gritty ${ }^{\mathrm{a}}$ & .12 & .27 & .52 & .30 & .29 \\
\hline Lambert, Hendricks \& Ross & Cloudburst & -.18 & .31 & .42 & .10 & .39 \\
\hline Royal Crown Revue & Park’s Place $^{\mathrm{a}}$ & -.09 & .40 & .41 & .19 & .37 \\
\hline Jeff Beck & Blue Wind & .01 & .10 & .15 & .80 & .12 \\
\hline Stanley Clarke & Rock'n Roll Jelly ${ }^{\mathrm{a}}$ & -.01 & .00 & .15 & .79 & .11 \\
\hline noJazz & Jungle Out & .07 & .01 & .30 & .56 & .38 \\
\hline Lidy Arbogast & Love to Love You Baby ${ }^{a}$ & .29 & .09 & .05 & .17 & .73 \\
\hline Ben Sidran & $\begin{array}{l}\text { Nothing Like The Sound Of } \\
\text { Bebop }^{\mathrm{a}}\end{array}$ & .18 & .10 & .10 & .18 & .73 \\
\hline
\end{tabular}


TABLE 3. Continued.

\begin{tabular}{llrrrrr}
\hline & & \multicolumn{4}{c}{ Principal component } \\
\cline { 4 - 7 } Artist & \multicolumn{1}{c}{ Piece } & $\mathrm{M}$ & $\mathrm{U}$ & $\mathrm{S}$ & $\mathrm{I}$ & $\mathrm{C}$ \\
\hline Herb Albert & Rise & .24 & .15 & .17 & .03 & $\mathbf{. 7 0}$ \\
Us3 & Cantaloop (Flip Fantasia) & .10 & .21 & .09 & -.05 & $\mathbf{. 7 0}$ \\
St. Germain & Pont Des Arts &. $\mathbf{4 3}$ & -.13 & .14 & .03 & $\mathbf{. 6 4}$ \\
Candy Dulfer & Sax-A-Go-Go & .25 & .08 & .26 & .25 & $\mathbf{. 6 3}$ \\
St. Germain & Rose Rouge & .10 & .16 & .46 & .10 & $\mathbf{. 5 5}$ \\
John Handy & Hard At Work & .42 & .31 & .18 & .09 & $\mathbf{. 5 2}$ \\
noJazz & Pick Up & .36 & -.01 & .35 & .15 & $\mathbf{. 5 1}$ \\
Room Eleven & One Of These Days & .37 & .24 & .15 & .04 & $\mathbf{. 5 0}$ \\
\hline
\end{tabular}

Note: $\mathrm{M}=$ Mellow; $\mathrm{U}=$ Unpretentious; $\mathrm{S}=$ Sophisticated; $\mathrm{I}=$ Intense; $\mathrm{C}=$ Contemporary. ${ }^{\mathrm{a}}=$ Piece was among the 25 administered to the undergraduate-student sample. Each piece's largest factor loading is in italics. Factor loadings $>|.40|$ are in bold typeface.

Internet sample, we conducted a PCA with varimax rotation on the 25 excerpts that were administered to the undergraduate sample. Next, we converted the factor loadings in both factor matrices to $z$-scores using Fisher's $r$-to- $z$ transformation. We then correlated the transformed factor loadings. The results revealed a high degree of convergence across the factors, with congruence coefficients $=.96, .94$, $.97, .68$, and .94, for M, U, S, I, and C, respectively.

These results strongly suggest that preferences for jazz music are shaped by affective reactions to the music and not to the genre classification or social connotations. We next compared the musical attributes that defined the jazz-preference factors with the musical attributes for the factors observed in Study 1 to determine whether the attributes that define and differentiate the MUSIC dimensions are the same across genres.

Attribute analysis. As in Study 1, we examined associations between the jazz preference factors and the musical attributes by correlating the factor loadings of the jazz excerpts in the Internet and undergraduate samples with the mean of the judges' ratings of the soundrelated and psychological attributes of the excerpts. The results in Table 4 show the patterns of correlations between the preference factors and the attributes. As can be seen in the first data column, the excerpts with high loadings on the Mellow factor were perceived as quiet, slow, clear sounding and to use synthesized sounds. In terms of psychological characteristics, the excerpts were perceived as having positive affect low in potency, as they were perceived as dreamy and romantic, but not strong or enthusiastic; Mellow jazz was also perceived as low in negative affect, as indicated by the negative correlations with many of the negative affect variables; a strong and consistent pattern of correlations appeared with the energy attributes, suggesting that the excerpts were low in energy; and the pieces were generally considered cerebral, with positive associations with the reflective, thoughtful, and deep attributes.

As can be seen in the second data column, the jazz excerpts with high loadings on the Unpretentious factor were perceived as slow, quiet, clear sounding, and lacking heavy bass and density, and as having primarily vocals and fewer electric instruments. No particularly strong correlations emerged among the positive affect attributes, but the excerpts were perceived as low in negative affect, with negative correlations with aggressive and abrasive; the Unpretentious jazz pieces were also perceived as being low in energy, with negative associations to forceful and party music; and the pieces were perceived as thoughtful but not complex.

The third data column shows the associations between the Sophisticated jazz factor and the attributes. The pieces with high loadings on this factor were perceived as fast, loud, and lacking heavy bass; the pieces were also perceived as having sounds produced by non-electric instruments, pianos, woodwinds, and as not having vocals. In terms of psychological characteristics, the pieces were perceived as having positive affect high in potency, as indicated by the strong correlations with enthusiastic and strong; the excerpts were positively related to many of the negative affect variables, suggesting the pieces were perceived as aggressive; the excerpts on this factor were also perceived as being high in energy, as the pieces were perceived as lively, manic, and forceful; they were also perceived as complex and intelligent, but not thoughtful or deep.

The correlations between the Intense jazz factor and the attributes are shown in the fourth data column. The excerpts with high factor loadings on this factor were perceived as very loud, fast, distorted, dense, and percussive, and the instruments were predominantly electric. The pieces were perceived as high in positive affect with high potency, as 
TABLE 4. Correlations Between the Jazz MUSIC Factor Loadings in Study 2 and Musical Attributes.

\begin{tabular}{|c|c|c|c|c|c|}
\hline Attributes & M & $\mathrm{U}$ & $S$ & I & $\mathrm{C}$ \\
\hline \multicolumn{6}{|l|}{ Sound-related } \\
\hline \multicolumn{6}{|c|}{ Auditory features } \\
\hline Dense & $-.26^{\star}$ & $-.39^{\star}$ & .15 & $.29^{*}$ & $.37^{\star}$ \\
\hline Distorted & $-.58^{\star}$ & $.25^{\star}$ & .07 & $.38^{*}$ & -.06 \\
\hline Fast & $-.66^{*}$ & $-.31^{\star}$ & $.59^{*}$ & $.39^{*}$ & .19 \\
\hline Heavy bass & -.06 & $-.38^{\star}$ & $-.35^{\star}$ & .11 & $.66^{\star}$ \\
\hline Loud & $-.67^{\star}$ & $-.29^{*}$ & $.34^{*}$ & $.52^{*}$ & $.27^{\star}$ \\
\hline Percussive & $-.27^{\star}$ & $-.57^{\star}$ & .18 & $.24^{\star}$ & $.49^{\star}$ \\
\hline \multicolumn{6}{|l|}{ Instruments } \\
\hline Brass & $-.31^{\star}$ & $.26^{*}$ & .14 & -.01 & -.09 \\
\hline Electric & .07 & $-.63^{\star}$ & $-.33^{\star}$ & $.39^{*}$ & $.55^{\star}$ \\
\hline Instrumental & .10 & $-.25^{\star}$ & $.37^{\star}$ & $.31^{*}$ & $-.32^{\star}$ \\
\hline Piano & -.16 & -.01 & $.56^{\star}$ & $-.29^{*}$ & -.20 \\
\hline Raspy voice & -.03 & .12 & $-.34^{*}$ & -.20 & $.23^{\star}$ \\
\hline Synthesizer & $.49^{*}$ & $-.57^{\star}$ & $-.42^{\star}$ & -.07 & $.51^{\star}$ \\
\hline Woodwind & .07 & -.07 & $.24^{\star}$ & -.15 & -.06 \\
\hline Yelling voice & $-.27^{\star}$ & $.37^{\star}$ & -.15 & -.15 & .03 \\
\hline \multicolumn{6}{|l|}{ Comparisons ${ }^{\mathrm{a}}$ with } \\
\hline Study 1 & $.63^{*}$ & .33 & $.41^{*}$ & $.69^{\star}$ & $.64^{\star}$ \\
\hline \multicolumn{6}{|l|}{ Psychological } \\
\hline \multicolumn{6}{|l|}{ Positive affect } \\
\hline Amusing & $-.59^{*}$ & .10 & .16 & .21 & $.29^{\star}$ \\
\hline Animated & $-.71^{\star}$ & -.14 & $.41^{\star}$ & $.43^{*}$ & $.24^{\star}$ \\
\hline Dreamy & $.77^{\star}$ & .00 & $-.55^{\star}$ & $-.39^{\star}$ & -.14 \\
\hline Enthusiastic & $-.66^{*}$ & -.14 & $.58^{\star}$ & $.33^{*}$ & .18 \\
\hline Fun & $-.41^{\star}$ & .13 & .08 & .22 & $.24^{\star}$ \\
\hline Happy & $-.31^{\star}$ & .03 & $.26^{*}$ & .11 & .19 \\
\hline Inspiring & .11 & .18 & .09 & -.06 & $-.35^{\star}$ \\
\hline Joyful & $-.35^{\star}$ & .04 & $.30^{\star}$ & .09 & .08 \\
\hline Merry & $-.41^{\star}$ & .09 & $.33^{\star}$ & .18 & .02 \\
\hline Romantic & $.72^{\star}$ & -.01 & $-.53^{\star}$ & $-.41^{\star}$ & -.05 \\
\hline Sensual & $.72^{\star}$ & -.10 & $-.39^{*}$ & $-.53^{*}$ & -.06 \\
\hline Strong & $-.67^{\star}$ & -.11 & $.55^{*}$ & $.38^{*}$ & .02 \\
\hline Warm & $.62^{*}$ & .15 & $-.43^{*}$ & $-.52^{\star}$ & -.01 \\
\hline \multicolumn{6}{|l|}{ Negative affect } \\
\hline Abrasive & $-.64^{\star}$ & $-.23^{\star}$ & $.34^{*}$ & $.53^{*}$ & .16 \\
\hline Aggressive & $-.69^{*}$ & $-.29^{*}$ & $.56^{\star}$ & $.47^{\star}$ & .19 \\
\hline Angry & $-.65^{\star}$ & -.15 & $.44^{*}$ & $.53^{\star}$ & -.05 \\
\hline Depressing & .17 & -.04 & $-.24^{*}$ & -.05 & -.09 \\
\hline Intense & $-.68^{\star}$ & -.19 & $.51^{\star}$ & $.45^{\star}$ & .04 \\
\hline Sad & $.34^{*}$ & .20 & $-.37^{\star}$ & -.22 & $-.25^{\star}$ \\
\hline Tense & $-.60^{*}$ & -.20 & $.45^{\star}$ & $.39^{*}$ & .04 \\
\hline \multicolumn{6}{|l|}{ Energy } \\
\hline Calming & $.75^{\star}$ & .10 & $-.33^{*}$ & $-.46^{*}$ & $-.33^{\star}$ \\
\hline
\end{tabular}


TABLE 4. Continued.

\begin{tabular}{|c|c|c|c|c|c|}
\hline Attributes & $\mathrm{M}$ & U & S & I & $\mathrm{C}$ \\
\hline Danceable & $.30^{*}$ & .01 & $-.63^{*}$ & $-.23^{*}$ & $.49^{\star}$ \\
\hline Forceful & $-.67^{*}$ & $-.34^{*}$ & $.46^{\star}$ & $.52^{\star}$ & .21 \\
\hline Gentle & $.82^{*}$ & .12 & $-.57^{\star}$ & $-.43^{*}$ & -.18 \\
\hline Lively & $-.70^{*}$ & -.12 & $.57^{\star}$ & $.39^{*}$ & .15 \\
\hline Manic & $-.71^{\star}$ & -.21 & $.54^{*}$ & $.49^{*}$ & .09 \\
\hline Mellow & $.82^{*}$ & .02 & $-.48^{*}$ & $-.47^{\star}$ & -.20 \\
\hline Party music & $-.32^{\star}$ & $-.31^{\star}$ & -.09 & $.24^{*}$ & $.60^{*}$ \\
\hline Relaxing & $.76^{*}$ & -.01 & $-.54^{\star}$ & $-.36^{*}$ & -.10 \\
\hline Thrilling & $-.62^{*}$ & -.18 & $.35^{\star}$ & $.53^{*}$ & .12 \\
\hline \multicolumn{6}{|l|}{ Cerebral } \\
\hline Complex & $-.50^{*}$ & $-.26^{*}$ & $.61^{*}$ & $.32^{*}$ & -.02 \\
\hline Deep & $.51^{\star}$ & .04 & $-.38^{*}$ & $-.33^{*}$ & -.11 \\
\hline Intelligent & .11 & .00 & $.26^{*}$ & -.22 & $-.26^{\star}$ \\
\hline Reflective & $.83^{\star}$ & -.02 & $-.42^{\star}$ & $-.44^{*}$ & $-.24^{\star}$ \\
\hline Sophisticated & $.51^{\star}$ & -.03 & -.10 & $-.47^{\star}$ & -.14 \\
\hline Thoughtful & $.49^{*}$ & $.24^{*}$ & $-.50^{\star}$ & $-.43^{*}$ & -.12 \\
\hline \multicolumn{6}{|l|}{ Comparisons $^{\mathrm{a}}$ with } \\
\hline Study 1 & $.95^{\star}$ & $.84^{*}$ & $-.40^{*}$ & $.90^{*}$ & $.55^{\star}$ \\
\hline
\end{tabular}

Note: Cell entries are correlations between the factor loadings (standardized using Fisher's $r$-to- $z$ transformation) of the excerpts used in Study 2 and the mean attribute ratings of the excerpts. $\mathrm{M}=$ Mellow; $\mathrm{U}=$ Unpretentious; $\mathrm{S}=$ Sophisticated; $\mathrm{I}=$ Intense $\mathrm{C}=$ Contemporary. ${ }^{\mathrm{a}}=$ Column-vector correlations comparing the patterns of $\mathrm{z}$-transformed correlations. $\mathrm{M}=$ Mellow; $\mathrm{U}=$ Unpretentious; $\mathrm{S}=$ Sophisticated; $\mathrm{I}=$ Intense; $\mathrm{C}=$ Contemporary. $N=75 .{ }^{*} p<.05$.

indicated by positive associations with animated and strong, but negative links with sensual, warm, and romantic; the pieces were perceived as high in negative affect, as reflected by the positive correlations with most of the attributes in that category; they were also perceived as very high in energy, as indicated by the strong positive correlations with thrilling and forceful; and the Intense pieces were perceived as complex, but low in all the other cerebral attributes.

Finally, as can be seen in the fifth data column, the jazz excerpts on the Contemporary factor were perceived as having heavy bass, percussion, and dense synthetic sounds, with electric instruments. The excerpts on this factor were perceived as amusing, fun, but not inspiring; they were thought to be low in sadness, and to have some energy, as reflected by the positive correlations with the party music and danceable attributes; and the pieces were not perceived as especially cerebral, as indicated by a negative relationships with the intelligent and reflective variables.

The patterns of correlations between the jazz MUSIC factors and the attributes appear quite similar to the patterns of correlations observed in Study 1. To formally test the degree of similarity, we standardized the correlation coefficients reported in Tables 2 and 4 using Fisher's $r$-to- $z$ transformation and then computed the column-vector correlations for each of the factors. The analyses revealed considerable convergence and discrimination between the corresponding mixed-genre and jazz factors in terms their sound-related characteristics (column-vector correlations $=.63, .33, .41, .69$, and .64, M, U, S, I, and C, respectively; mean off-diagonal correlation $=-.18$ ), as well as their psychological characteristics (column-vector correlations = $.95, .84,-.40, .90$, and $.55, \mathrm{M}, \mathrm{U}, \mathrm{S}, \mathrm{I}$, and C, respectively; mean off-diagonal correlation $=-.16$ ). The one exception was for the Sophisticated jazz factor. Close inspection of the psychological correlates of this factor suggested that the pieces were more dynamic in the sense that they expressed stronger forms of positive and negative affect and more energy, compared to the pieces on the mixed-genre Sophisticated factor. The pieces were also perceived as less thoughtful and deep, yet intelligent and more complex than the mixed-genre pieces. In general, these results suggest that at least four of the five jazz-preference factors clearly resemble the MUSIC factors.

Summary. The present results supported our hypothesis and revealed five jazz-preference factors. Although the MUSIC labels may not provide the best descriptors for the jazz-preference factors, analyses of the attributes associated with the factors indicated that most of the factors were defined by attributes that resembled the dimensions observed in Study 1. Indeed, Mellow and Intense showed the greatest 
degree of convergence on both the sound and psychological attributes. However, the results were comparatively weaker for Sophisticated, which showed no convergence on the psychological attributes but reasonable convergence on the sound-related attributes. The lack of strong convergence for the Sophisticated factor may reflect something intrinsically different in the way people perceive jazz. Alternatively, the differences may simply reflect the different contrast sets employed in the two different studies: in Study 1, jazz was being compared to a heterogeneous set of mixed-genre music, and in the present study jazz was being compared only to other jazz. However, jazz is a style of music that does not have a large commercial audience, and it tends to skew toward an older audience (North \& Hargreaves, 2007). Thus, if we are to rigorously examine the notion that preferences are based on five particular combinations of attributes it would be instructive to examine preferences for a style of music that has a larger and more diverse fanbase.

\section{Study 3: The Structure of Preferences for Rock Music}

We conducted this study as a further test of the hypothesis that the MUSIC model reflects individual differences in preferences for particular combinations of musical characteristics. To test the hypothesis, we assessed individual differences in preferences for a variety of rock musical pieces. We chose to examine preferences for rock music because it is one of the most popular music genres, especially among young people (North \& Hargreaves, 2007). And there exist more clearly defined stereotypes about rock music fans (e.g., aggressive, hedonistic), compared to jazz fans (Rentfrow \& Gosling, 2007; Rentfrow et al., 2009), suggesting that there might be tighter social constraints for rock musical preferences. For these reasons, investigating individual differences in preferences for rock music should provide a more conservative test of our hypothesis.

\section{METHOD}

Participants. As in Study 2, we collected data for an Internet sample and an undergraduate student sample.

The Internet sample was recruited using the same methods used in Studies 1 and 2. Of the active "My Personality" users, 1,786 volunteered to complete the rock music-preference measure. Of those who indicated, $642(38 \%)$ were male and 1,030 (62\%) were female. The sample ranged in age from 18 to 59 and comprised mostly young adults, with mean age $=24.07$ and median age $=22(S D=6.86)$.

The undergraduate student sample comprised students at the University of Texas at Austin enrolled in an introductory psychology course during the 2010 Fall semester. Students were invited to complete a musical preference measure. These were not the same students who participated in Study 2. There were 374 students who chose to participate. Of those who indicated, 140 (39\%) were male and $215(61 \%)$ were female. Information about participants' age was not collected. However, the median age for previous semesters was 18 and because the demographic composition of this sample was not noticeably different from previous semesters, it is likely that the median age of this sample was also 18.

Procedure. The procedures for both the Internet and student samples were identical to the procedure in Study 2.

Musical preference stimuli. The same multistep procedure used in Study 2 was used to select rock music excerpts. The procedure resulted in a set of 50 rock music excerpts. Participants in the Internet sample reported their degree of liking for the excerpts using a 9-point rating scale, with endpoints at 1 (extremely dislike) and 9 (extremely like). And participants in the university sample reported their degree of liking for 25 of the pieces using a 5-point rating scale with endpoints at 1 (extremely dislike) and 5 (extremely like). The 50 pieces administered to the Internet sample and the 25 pieces administered to the university sample are listed in Table 5 . The clips are available from the authors on request.

Musical attributes. The rock pieces were coded on the same 50 attributes using the same procedures as in Studies 1 and 2. Fifty judges with no formal music training independently rated the 50 jazz excerpts; no judge rated all of the excerpts or attributes (mean number of judges per excerpt $=8$; range: $5-12$ ). Analyses of interjudge agreement revealed high attribute consensus (i.e., Cronbach's alpha) for the sound-related attributes $(M$ alpha $=.88)$, with the highest agreement for instrumental $(M$ alpha $=.97)$ and the lowest agreement for dense $(M$ alpha $=.61)$. Attribute agreement was also high for the psychologically oriented attributes $(M$ alpha $=.78)$, with the highest agreement for angry $(M$ alpha $=.91)$ and the lowest agreement for complex $(M$ alpha $=.34)$.

\section{RESULTS AND DISCUSSION}

Factor analysis. For both the Internet and student samples, multiple criteria were used to determine the number of factors to retain. For the Internet sample, a PCA with varimax rotation of the 50 excerpts yielded a large first factor that accounted for $24 \%$ of the variance; parallel analysis of random data suggested that the first six eigenvalues were greater than chance; and the scree plot suggested "elbows" at roughly four and six factors. For the university sample, a PCA with varimax rotation of the 25 excerpts yielded a large first factor that accounted for $22 \%$ of the variance; 
TABLE 5. Five Varimax-Rotated Principal Components Derived from 50 Rock Music Excerpts.

\begin{tabular}{|c|c|c|c|c|c|c|}
\hline \multirow[b]{2}{*}{ Artist } & \multirow[b]{2}{*}{ Piece } & \multicolumn{5}{|c|}{ Principal component } \\
\hline & & M & $\mathrm{U}$ & S & I & $\mathrm{C}$ \\
\hline Radiohead & No Surprises & .81 & .12 & .04 & .00 & .08 \\
\hline Radiohead & Fake Plastic Trees & .79 & .11 & .02 & .01 & .13 \\
\hline Radiohead & Reckoner & .73 & .09 & .18 & .12 & .08 \\
\hline Radiohead & Back Drifts & .72 & -.03 & .02 & .22 & -.03 \\
\hline Radiohead & Nude & .66 & .11 & .29 & -.05 & .11 \\
\hline Jeff Buckley & Dream Brother & .65 & .02 & .13 & .20 & .19 \\
\hline Radiohead & Weird Fishes/Arpeggi & .64 & .07 & .38 & .00 & .06 \\
\hline Death in Vegas & Girls $^{\mathrm{a}}$ & .62 & .12 & .18 & -.06 & .17 \\
\hline Arcade Fire & Deep Blue & .60 & .16 & .18 & .04 & .24 \\
\hline Radiohead & 15 Step & .58 & .10 & .35 & .03 & .05 \\
\hline Jeff Buckley & Hallelujah $^{\mathrm{a}}$ & .53 & .19 & -.01 & -.08 & .29 \\
\hline Beck & Guess I'm Doing Fine & .46 & .18 & .10 & .17 & .38 \\
\hline The Beatles & Eleanor Rigby ${ }^{a}$ & .40 & .30 & .03 & .02 & .38 \\
\hline The Beatles & Honey Don't ${ }^{\mathrm{a}}$ & .13 & .81 & .08 & -.02 & .19 \\
\hline Led Zeppelin & Hot Dog & .00 & .78 & .22 & .07 & .10 \\
\hline The Beatles & Act Naturally & .09 & .77 & .03 & -.03 & .14 \\
\hline Jeff Buckley & Parchman Farm Blues ${ }^{\mathrm{a}}$ & .33 & .76 & .03 & .00 & .05 \\
\hline Led Zeppelin & Bron-Yr-Aur Stomp ${ }^{a}$ & .23 & .75 & .07 & .06 & .10 \\
\hline Simon \& Garfunkel & Kodachrome/Maybellene & .11 & .68 & .17 & .13 & .19 \\
\hline Led Zeppelin & Boogie with Stu & .11 & .63 & .18 & .11 & .30 \\
\hline The RH Factor & Rich Man's Welfare ${ }^{a}$ & .23 & .15 & .74 & .06 & -.01 \\
\hline Hall \& Oates & One on One ${ }^{a}$ & .11 & .06 & .70 & -.18 & .35 \\
\hline Dave Mathews Band & Lover Lay Down ${ }^{\mathrm{a}}$ & .29 & .12 & .65 & -.17 & .24 \\
\hline Frank Zappa & Inca Roads ${ }^{a}$ & .32 & .11 & .63 & .06 & -.03 \\
\hline Phish & You Enjoy Myself & .12 & .21 & .59 & .20 & .27 \\
\hline Led Zeppelin & Black Mountain Side & .39 & .28 & .43 & .12 & -.05 \\
\hline Mark Ronson & L.S.F. ${ }^{\mathrm{a}}$ & .31 & .31 & .41 & .21 & .20 \\
\hline Queens of the Stone Age & Tension Head ${ }^{\mathrm{a}}$ & -.01 & -.11 & .06 & .81 & .03 \\
\hline Queens of the Stone Age & Battery Acid & .08 & .07 & -.01 & .80 & -.02 \\
\hline Ministry & Burning Inside & -.10 & -.08 & .00 & .80 & -.06 \\
\hline Jeff Buckley & Eternal Life $^{a}$ & .03 & .04 & .08 & .80 & .05 \\
\hline Jeff Buckley & Kick Out the Jams & .02 & .10 & .02 & .79 & .01 \\
\hline Queens of the Stone Age & Quick \& to the Pointless ${ }^{\mathrm{a}}$ & .00 & -.04 & -.08 & .78 & -.13 \\
\hline Queens of the Stone Age & Misfit Love & .07 & .01 & .08 & .78 & .02 \\
\hline Radiohead & Body Snatchers ${ }^{\mathrm{a}}$ & .20 & .12 & .02 & .73 & -.13 \\
\hline Queen & The Invisible Man ${ }^{\mathrm{a}}$ & -.06 & .04 & .24 & .71 & .06 \\
\hline Red Hot Chili Peppers & Higher Ground $^{\mathrm{a}}$ & -.04 & .05 & .00 & .71 & .26 \\
\hline Rage Against the Machine & Bombtrack & .05 & .04 & -.12 & .64 & .10 \\
\hline Beastie Boys & Sabotage $^{\mathrm{a}}$ & .12 & -.02 & -.19 & .63 & .09 \\
\hline The Stooges & Down on the Street ${ }^{\mathrm{a}}$ & .07 & .38 & .13 & .56 & .30 \\
\hline Radiohead & Electioneering & .45 & .12 & -.06 & .52 & -.03 \\
\hline
\end{tabular}


TABLE 5. Continued.

\begin{tabular}{|c|c|c|c|c|c|c|}
\hline \multirow[b]{2}{*}{ Artist } & \multirow[b]{2}{*}{ Piece } & \multicolumn{5}{|c|}{ Principal component } \\
\hline & & M & $\mathrm{U}$ & S & I & $\mathrm{C}$ \\
\hline Primus & $\begin{array}{l}\text { Jerry was a Race Car } \\
\text { Driver }^{\mathrm{a}}\end{array}$ & .18 & .27 & .08 & .39 & .03 \\
\hline Ozomatli & Saturday Night & .04 & .03 & .12 & .26 & .19 \\
\hline The Police & $\begin{array}{l}\text { Wrapped Around Your } \\
\text { Finger }^{\mathrm{a}}\end{array}$ & .19 & .06 & .28 & .04 & .68 \\
\hline Queen & Under Pressure & .24 & .15 & -.07 & .12 & .64 \\
\hline Queen & $\begin{array}{l}\text { Crazy Little Thing Called } \\
\text { Love }\end{array}$ & .16 & .40 & -.01 & -.03 & .64 \\
\hline Prince & When Doves Cry ${ }^{\mathrm{a}}$ & .15 & .05 & .11 & -.01 & .63 \\
\hline The Doobie Brothers & Listen to the Music ${ }^{a}$ & .06 & .42 & .24 & -.07 & .59 \\
\hline Lynyrd Skynyrd & Gimmie Three Steps ${ }^{\mathrm{a}}$ & -.09 & .43 & .07 & .26 & .54 \\
\hline Pink Floyd & Comfortably Numb & .31 & .20 & .11 & .09 & .53 \\
\hline
\end{tabular}

Note: $\mathrm{M}=$ Mellow; $\mathrm{U}=$ Unpretentious; $\mathrm{S}=$ Sophisticated; $\mathrm{I}=$ Intense; $\mathrm{C}=$ Contemporary. ${ }^{\mathrm{a}}=$ Piece was among the 25 administered to the undergraduate-student sample. Each piece's largest factor loading is in italics. Factor loadings $\geq|.40|$ are in bold typeface.

and the scree plot suggested an "elbow" at roughly six factors. For both samples, factor invariance across extraction methods revealed very high convergence across the PCA, PA, and ML extraction methods, with correlations averaging above .999. Comparisons of factor scores derived from PCAs with orthogonal and oblique rotations revealed high convergence across rotation methods, with correlations across the corresponding MUSIC factors averaging 98 .

To determine how many factors to retain, we again examined four, five, and six-factor solutions. The fourfactor models yielded a structure with a fourth factor comprising several excerpts with substantial factor loadings on multiple factors and was difficult to interpret; the five-factor model revealed five interpretable factors with good factor saturation; and the six-factor model generated a factor composed of four musical excerpts, two of which had very large secondary loadings. Based on these findings, we elected to retain the first five music-preference factors obtained in both samples.

As can be seen in the five-factor solution reported in Table 5 , there was a factor resembling Mellow, with excerpts of alternative and soft rock by artists such as Radiohead, Jeff Buckley, and Arcade Fire. There was also a factor similar to the Unpretentious factor that comprised excerpts of classic rock and country rock by artists such as the Beatles, Led Zeppelin, and Simon and Garfunkel. A third factor emerged that reflected the Sophisticated dimension, with pieces of jazz-rock, fusion, and avant-garde rock by artists including The RH Factor, Frank Zappa, and Phish. A fourth factor resembling Intense and comprising excerpts of heavy, industrial, and punk excerpts by artists like Queens of the Stone Age, Ministry, and Red Hot Chili Peppers. And the fifth factor comprised excerpts of progressive rock, synthpop, and new wave pieces by artists such as the Police, Queen, and Prince, appearing similar to the Contemporary factor.

The five factors that emerged in the undergraduate student sample were very similar to the factors in the Internet sample. We empirically examined the degree of similarity between the structures by comparing the patterns of factor loadings for 25 excerpts that were administered to both samples, in the same way reported in Study 2. The results revealed a high degree of convergence across the factors, with congruence coefficients = $.86, .98, .92, .98$, and .85 , for $\mathrm{M}, \mathrm{U}, \mathrm{S}, \mathrm{I}$, and C, respectively.

Attribute analysis. The results in Table 6 show the patterns of correlations between the rock preference factors and the attributes. The patterns of correlations in the first data column indicate that the excerpts with high loadings on the Mellow factor were perceived as slow, quiet, clear sounding, and airy, and to use acoustic instruments and synthesized sounds. In terms of psychological characteristics, the excerpts were perceived as having positive affect low in potency, with positive correlations with dreamy and romantic, but not animated or enthusiastic; Mellow rock was negatively correlated with most of the negative affect descriptors except sad and depressing; a strong and consistent pattern of correlations appeared with the energy attributes, suggesting that the excerpts were low in energy; and the pieces were generally considered cerebral, with positive associations with the thoughtful, deep, and reflective descriptors.

The Unpretentious rock pieces were perceived as airy and clear sounding with little percussion, and as having primarily acoustic instruments. The excerpts were also perceived as having some degree of positive affect, as 
180 Peter J. Rentfrow, Lewis R. Goldberg, David J. Stillwell, Michal Kosinski, Samuel D. Gosling, \& Daniel J. Levitin

TABLE 6. Correlations Between the Rock MUSIC Factor Loadings in Study 3 and Musical Attributes.

\begin{tabular}{|c|c|c|c|c|c|}
\hline Attributes & M & $\mathrm{U}$ & $S$ & I & $\mathrm{C}$ \\
\hline \multicolumn{6}{|l|}{ Sound-related } \\
\hline \multicolumn{6}{|l|}{ Auditory features } \\
\hline Dense & $-.24^{*}$ & $-.49^{\star}$ & .11 & $.42^{*}$ & -.10 \\
\hline Distorted & $-.30^{*}$ & $-.48^{*}$ & $-.48^{\star}$ & $.88^{*}$ & $-.39^{*}$ \\
\hline Fast & $-.61^{\star}$ & -.16 & $-.24^{\star}$ & $.75^{\star}$ & $-.29^{\star}$ \\
\hline Heavy bass & $-.47^{\star}$ & $-.34^{*}$ & -.01 & $.48^{*}$ & .08 \\
\hline Loud & $-.52^{\star}$ & $-.34^{*}$ & $-.28^{\star}$ & $.83^{*}$ & $-.32^{\star}$ \\
\hline Percussive & $-.53^{\star}$ & $-.49^{*}$ & -.07 & $.71^{\star}$ & -.06 \\
\hline \multicolumn{6}{|l|}{ Instruments } \\
\hline Brass & -.01 & .02 & .10 & -.04 & .10 \\
\hline Electric & $-.37^{\star}$ & $-.58^{*}$ & $-.30^{*}$ & $.77^{\star}$ & -.07 \\
\hline Instrumental & $-.25^{\star}$ & -.15 & $.53^{*}$ & .16 & $-.24^{*}$ \\
\hline Piano & .06 & .19 & $.23^{*}$ & -.17 & -.09 \\
\hline Raspy voice & -.19 & -.06 & $-.32^{\star}$ & $.37^{\star}$ & -.20 \\
\hline Synthesizer & $.29^{*}$ & $-.34^{*}$ & $.22^{\star}$ & -.20 & -.02 \\
\hline Woodwind & -.07 & -.13 & $.67^{\star}$ & $-.28^{*}$ & .09 \\
\hline Yelling voice & $-.29^{*}$ & .02 & $-.46^{\star}$ & $.49^{*}$ & -.10 \\
\hline \multicolumn{6}{|l|}{ Comparisons $^{\mathrm{a}}$ with } \\
\hline Study 1 & $.79^{\star}$ & $.42^{\star}$ & $.73^{\star}$ & $.91^{*}$ & $.50^{\star}$ \\
\hline Study 2 & $.70^{\star}$ & $.65^{\star}$ & .16 & $.81^{\star}$ & .28 \\
\hline \multicolumn{6}{|l|}{ Psychological } \\
\hline \multicolumn{6}{|l|}{ Positive affect } \\
\hline Amusing & $-.31^{\star}$ & $.56^{\star}$ & -.18 & -.14 & $.23^{\star}$ \\
\hline Animated & $-.48^{*}$ & $.34^{*}$ & -.02 & .11 & .01 \\
\hline Dreamy & $.71^{\star}$ & -.01 & $.30^{*}$ & $-.75^{\star}$ & $.28^{\star}$ \\
\hline Enthusiastic & $-.46^{*}$ & .19 & -.19 & .14 & $.22^{*}$ \\
\hline Fun & $-.34^{\star}$ & $.35^{*}$ & -.15 & -.10 & $.37^{\star}$ \\
\hline Happy & $-.24^{*}$ & $.44^{\star}$ & .04 & $-.28^{*}$ & $.31^{\star}$ \\
\hline Inspiring & $.38^{*}$ & .10 & .13 & $-.69^{*}$ & $.56^{*}$ \\
\hline Joyful & -.06 & $.56^{\star}$ & $.41^{\star}$ & $-.62^{*}$ & .20 \\
\hline Merry & -.17 & $.56^{*}$ & $.34^{*}$ & $-.48^{\star}$ & .15 \\
\hline Romantic & $.56^{\star}$ & -.07 & $.40^{*}$ & $-.71^{\star}$ & $.30^{*}$ \\
\hline Sensual & $.26^{\star}$ & -.07 & $.34^{*}$ & $-.46^{*}$ & $.26^{*}$ \\
\hline Strong & $-.38^{\star}$ & $-.40^{*}$ & -.20 & $.54^{*}$ & -.07 \\
\hline Warm & $.41^{\star}$ & $.23^{\star}$ & $.49^{*}$ & $-.82^{*}$ & $.26^{\star}$ \\
\hline \multicolumn{6}{|l|}{ Negative affect } \\
\hline Abrasive & $-.43^{*}$ & $-.31^{*}$ & $-.38^{\star}$ & $.86^{\star}$ & $-.52^{*}$ \\
\hline Aggressive & $-.49^{\star}$ & $-.33^{\star}$ & $-.49^{*}$ & $.87^{\star}$ & $-.34^{*}$ \\
\hline Angry & $-.42^{*}$ & $-.37^{\star}$ & $-.53^{*}$ & $.89^{*}$ & $-.36^{*}$ \\
\hline Depressing & $.54^{\star}$ & -.17 & $-.27^{\star}$ & -.03 & -.15 \\
\hline Intense & $-.38^{*}$ & $-.56^{\star}$ & $-.28^{\star}$ & $.74^{*}$ & $-.24^{*}$ \\
\hline Sad & $.78^{*}$ & -.11 & .11 & $-.57^{\star}$ & .16 \\
\hline Tense & $-.32^{*}$ & $-.48^{\star}$ & $-.31^{\star}$ & $.71^{\star}$ & -.18 \\
\hline \multicolumn{6}{|l|}{ Energy } \\
\hline Calming & $.53^{\star}$ & .19 & $.33^{\star}$ & $-.75^{\star}$ & $.29^{*}$ \\
\hline Danceable & $-.35^{*}$ & .21 & -.19 & -.04 & $.47^{\star}$ \\
\hline Forceful & $-.54^{*}$ & $-.35^{\star}$ & $-.44^{*}$ & $.86^{*}$ & $-.25^{\star}$ \\
\hline Gentle & $.69^{\star}$ & .08 & $.27^{\star}$ & $-.77^{\star}$ & $.22^{\star}$ \\
\hline Lively & $-.56^{*}$ & $.30^{*}$ & -.11 & .14 & $.22^{*}$ \\
\hline Manic & $-.40^{*}$ & $-.35^{\star}$ & $-.39^{*}$ & $.82^{*}$ & $-.44^{\star}$ \\
\hline Mellow & $.64^{\star}$ & .13 & .21 & $-.72^{\star}$ & $.24^{\star}$ \\
\hline Party music & $-.43^{*}$ & .01 & $-.40^{*}$ & $.29^{*}$ & $.26^{*}$ \\
\hline Relaxing & $.53^{\star}$ & .00 & $.46^{\star}$ & $-.77^{\star}$ & $.28^{\star}$ \\
\hline Thrilling & $-.39^{\star}$ & -.14 & $-.31^{\star}$ & $.39^{*}$ & .14 \\
\hline
\end{tabular}


TABLE 6. Continued.

\begin{tabular}{|c|c|c|c|c|c|}
\hline Attributes & M & $\mathrm{U}$ & S & I & $\mathrm{C}$ \\
\hline \multicolumn{6}{|l|}{ Cerebral } \\
\hline Complex & -.03 & $-.29^{*}$ & $.28^{\star}$ & .11 & .00 \\
\hline Deep & $.67^{*}$ & -.09 & .06 & $-.57^{\star}$ & $.30^{*}$ \\
\hline Intelligent & $.54^{*}$ & -.04 & $.32^{*}$ & $-.73^{\star}$ & $.46^{*}$ \\
\hline Reflective & $.62^{*}$ & -.03 & .08 & $-.57^{\star}$ & $.26^{*}$ \\
\hline Sophisticated & $.52^{*}$ & -.10 & $.40^{*}$ & $-.68^{*}$ & $.32^{\star}$ \\
\hline Thoughtful & $.71^{*}$ & .04 & .03 & $-.68^{*}$ & $.30^{*}$ \\
\hline \multicolumn{6}{|l|}{ Comparisons ${ }^{\mathrm{a}}$ with } \\
\hline Study 1 & $.93^{*}$ & $.70^{*}$ & $.91^{*}$ & $.97^{\star}$ & .25 \\
\hline Study 2 & $.89^{*}$ & $.57^{\star}$ & $-.53^{*}$ & $.88^{\star}$ & -.19 \\
\hline
\end{tabular}

Note: Cell entries are correlations between the factor loadings (standardized using Fisher's $r$-to- $z$ transformation) of the excerpts used in Study 3 and the mean attribute ratings of the excerpts. $\mathrm{M}=$ Mellow; $\mathrm{U}=$ Unpretentious; $\mathrm{S}=$ Sophisticated; $\mathrm{I}=$ Intense $\mathrm{C}=$ Contemporary ${ }^{\mathrm{a}}=$ Column-vector correlations comparing the patterns of $\mathrm{z}$-transformed correlations.

$\mathrm{M}=$ Mellow; $\mathrm{U}=$ Unpretentious; $\mathrm{S}=$ Sophisticated; $\mathrm{I}=$ Intense; $\mathrm{C}=$ Contemporary. $N=75 .{ }^{*} p<.05$

reflected in the positive correlations with amusing, joyful, merry, and happy; the patterns of correlations were uniformly negative with the negative affect descriptors, suggesting that the excerpts were perceived as lacking negative affect; few significant correlations emerged among the energy descriptors, except negative correlations with forceful and manic; and the pieces were perceived as not complex.

The rock pieces with high loadings on the Sophisticated factor were perceived as clear sounding, quiet, and slow; the pieces were also perceived as having sounds produced by acoustic instruments, pianos, woodwinds, and as not having vocals. In terms of psychological characteristics, the pieces were perceived as having positive affect low in potency, as reflected by the positive correlations with warm and joyful; the excerpts were negatively related to almost all the negative affect variables; the pattern of correlations were among the energy descriptors suggested that the excerpts were perceived as low in energy, reflected by the positive correlations with relaxing and calming, and negative associations with forceful and party music; the excerpts were also positively associated with some of the cerebral descriptors, such as sophisticated, intelligent, and complex.

The excerpts with high factor loadings on the Intense factor were very strongly correlated with the dense, loud, fast, and percussive auditory descriptors, and the instruments were predominantly electric along with yelling and raspy vocals. The pieces were strongly and negatively correlated with most of the positive affect descriptors except strong, suggesting that Intense rock is low in positive affect; the pieces were strongly positively related to nearly all the negative affect descriptors except sad, suggesting the pieces were high in negative affect; the patterns of correlations clearly suggested that the pieces were very high in energy, with very strong correlations with forceful and manic; and the excerpts were negatively correlated with most of the cerebral descriptors.

Finally, the rock excerpts on the Contemporary factor were perceived as clear sounding and quiet with singing. The excerpts on this factor were positively related to almost all the positive affect descriptors; they were also rated as low in negative affect, as indicated by the negative correlations with nearly all the descriptors; the pieces were also perceived as danceable and yet relaxing; and the pieces were positively related to almost all the cerebral descriptors.

We next examined the degree to which the attributes associated with the rock preference factors resembled the patterns observed for the mixed genre and jazz preference factors using the same procedure described in Study 2. The analyses revealed a high degree of convergence and discrimination between the rock and mixed-genre factors for the sound-related characteristics (column-vector correlations $=.79, .42, .73, .91$, and $.50, \mathrm{M}, \mathrm{U}, \mathrm{S}, \mathrm{I}$, and $\mathrm{C}$ respectively; mean off-diagonal correlation $=-.13$ ) as well as for the psychological characteristics (columnvector correlations $=.93, .70, .91, .97$, and $.25, \mathrm{M}, \mathrm{U}, \mathrm{S}, \mathrm{I}$, and $\mathrm{C}$ respectively; mean off-diagonal correlation = -.11 ). There was also convergence across and discrimination between the corresponding rock and jazz factors for the sound-related characteristics (column-vector correlations $=.70, .65, .16, .81$, and $.28, \mathrm{M}, \mathrm{U}, \mathrm{S}, \mathrm{I}$, and C respectively; mean off-diagonal correlation $=-.21$ ), but only high convergence for three of the factors for the psychological-oriented attributes (column-vector correlations $=.89, .57,-.53, .88$, and $-.19, \mathrm{M}, \mathrm{U}, \mathrm{S}, \mathrm{I}$, and C respectively; mean off-diagonal correlation $=-.19$ ).

Summary. The results from this study once again support the hypothesis that individual differences in musical preferences are based on affective reactions to particular 
combinations of musical qualities in addition to genre classifications or social connotations. Indeed, results from the factor analyses revealed five rock-preference factors. Although the MUSIC labels may not provide the best descriptors for the five rock-preference factors, analyses of the attributes associated with the factors indicated that those factors were defined by attributes that resembled the preference models observed in Studies 1 and 2. The patterns of attribute correlations between the rock and mixed-genre factors were very similar, however, the degree of convergence was less between the rock and jazz-preference factors.

\section{General Discussion}

The primary aim of the present research was to replicate and extend theory and research on the structure of musical preferences. Using multiple pieces of music, methods, and samples, three studies were conducted to test the replicability of the five-dimensional music-preference model and to broaden the set of attributes that define and differentiate the factors. The results from all three studies displayed some degree of convergence to provide additional support for the five MUSIC preference factors. Indeed, the five factors are demonstrably not an artifact of genre classification, as evidenced by the results from Studies 2 and 3 , in which five music factors emerged in preferences for jazz and rock music, respectively. Furthermore, in 28 out of the $35(80 \%)$ attribute comparisons, the MUSIC factors displayed patterns of associations with the sound-related and psychological attributes that were significantly similar. Although the nature of some of the factors may not be entirely identical in every instance, in general, the factors appear to be comparable across genres. Taken together, these results provide almost complete replication of the MUSIC model and strongly suggest that individual differences in musical preferences are based largely on the sonic and psychological characteristics of the music.

\section{FUTURE DIRECTIONS}

The present findings are stimulating because they provide a foundation on which to examine additional important questions about the nature of musical preferences. With a robust empirically based framework for conceptualizing and measuring musical preferences, and clear evidence for the validity of using musical excerpts for measuring preferences, researchers can begin developing and testing hypotheses about the social, psychological, and musical factors that shape individuals' preferences for music.

Cross-cultural research on musical preferences. As the empirical study of musical preferences continues to develop, one important issue to examine concerns the role that culture plays in shaping preferences. The effects of culture on preferences must be far reaching. Indeed, the cultural contexts in which people live influence the types and varieties of music they are exposed to, the social meanings they attach to them, as well as the ways in which they use music (Cross, 2001). Therefore, if we are to develop a complete understanding of the nature of musical preferences, including its structure, it is crucial that we examine cultural differences in musical preferences.

There is some evidence to suggest that the MUSIC model may generalize to other cultures. Converging evidence for the cross-cultural generalizability of music preferences comes from independent investigations conducted in North America and Europe (Colley, 2008; Delsing et al., 2008, George et al., 2007; Rentfrow, Goldberg, \& Levitin, 2011; Rentfrow \& Gosling, 2003; Schäfer \& Sedlmeier, 2009). Although the investigations did not extract exactly the same number of factors, in all the samples studied there were factors that resembled Unpretentious, Sophisticated, Intense, and Contemporary. And in more than half the samples a factor resembling Mellow emerged. Nonetheless, future research should directly examine the degree to which the same-music preference factors emerge in different cultures.

A contribution of the present research is that it demonstrates that it is possible to reliably measure individual differences in musical preferences using audio excerpts of actual music, not simply genre labels or names of songs or artists. This methodology will facilitate research on culture and musical preferences by enabling researchers to measure participants' affective reactions to the same audio excerpts. Such an approach sidesteps many of the translation issues encountered in cross-cultural research and avoids the problems related to genre classifications. Of course, effectively examining the cross-cultural generalizability of the MUSIC model will require a much wider and more diverse selection of musical pieces than those included here, which were of predominantly Western origin.

Musical preferences throughout the lifespan. At various points throughout life, individuals experience certain events (e.g., graduate from college, get married, have children), assume particular social roles (employee, spouse, parent), and encounter new social environments (colleagues, friends, children). Such life events are so important that they contribute to changes in personality (Haan, Millsap, \& Hartka, 1986; Hogan, 1996). Considering that musical preferences are influenced by family and peers (Bešić \& Kerr, 2009; Delsing et al., 2008) 
and are linked to personality (Rentfrow \& Gosling, 2003; Zweigenhaft, 2008), it is likely that life events also influence individuals' musical preferences. Thus, investigating musical preferences throughout the lifespan will shed light on the social and psychological determinants of musical preferences.

Research on age trends in musical preferences (Delsing et al., 2008; Holbrook \& Schindler, 1989; LeBlanc, Sims, Siivola, \& Obert, 1996) has produced inconsistent and sometimes contradictory results. For example, some studies suggest that preferences crystallize during early adulthood (Holbrook \& Schindler, 1989) while others suggest that preferences continue to develop later in adulthood (LeBlanc et al., 1996). One reason for the discrepant findings might be because preferences were assessed quite differently across the studies, with some asking respondents to recall the names of their favorite artists at various points in time and others measuring preferences for music genres.

Using the MUSIC model, age trends could be examined for each of the music-preference factors to ascertain whether preferences change and when. Preferences for auditory excerpts could be measured instead of genre preferences so that participants need not remember the names of their favorite artists or be familiar with genre classifications. Longitudinal or cross-sectional research that assesses individual differences in musical preferences and also gathers information about life events has the potential to shed more light on the social and psychological factors that shape musical preferences.

Psychological correlates of musical preferences. There is growing evidence suggesting that musical preferences are linked to a range of personality traits, values, selfviews, and abilities (Delsing, et al., 2008; Rentfrow \& Gosling, 2003; Rentfrow, Goldberg, \& Zilca, 2011; Zweigenhaft, 2008). Results from this research suggest that preferences for classical music are associated with traits such as curiosity, liberal political values, and intelligence; and preferences for country music are associated with traits such as friendliness, traditional values, and conservatism. Overall, these results suggest that musical preferences are manifestations of personality. Considering the robustness of the MUSIC model and the consistent results reported in previous research, it is likely that the patterns of correlations between personality traits and preferences for the MUSIC factors will be similar to past work.

However, measuring preferences for the MUSIC factors using auditory excerpts has the added advantage of enabling researchers to examine associations between personality and preferences for the musical attributes. Specifically, weighting affective reactions to musical excerpts by the scores for each of the attributes (e.g., fast, sad, aggressive, etc.) reveals individuals' degree of preferences for the attributes. These attribute preferences can then be correlated with personality and individual difference variables to develop a more nuanced understanding of the psychological correlates of musical preferences.

The emerging picture from work on the neurochemistry of music indicates that music modulates levels of oxytocin, serotonin, epinephrine, prolactin, and dopamine (see Chanda \& Levitin, 2011, for a review). Particular musical features have been shown to be associated with distinct neurochemical systems. For example, soothing and comforting music are linked to prolactin, pleasurable music to dopamine, and patriotic songs to oxytocin. Of course there is a layer of subjectivity in even these relatively objective neurochemical measures: music that one person finds soothing may be considered irritating to another, and one person's workout music may cause another to fall asleep. Further research may uncover additional links between particular musical attributes and neurochemical reactions.

CONCLUSION

Theory and research in music psychology has focused considerable attention on the psychological, physiological, cognitive, and neurological correlates of musical preferences. Findings from that work demonstrate clearly the significance of music in people's lives. The present work attempted to extend that important research by developing a more nuanced understanding of musical preferences. Our results strongly suggest that musical preferences can be conceptualized in terms of the five MUSIC factors and that those factors are defined and differentiated by specific combinations of sound-related and psychological attributes.

\section{Author Note}

This research was funded by Grant AG20048 from the National Institute on Aging, National Institutes of Health, U.S. Public Health Service to LRG; and by Grant 22817509 from the National Science and Engineering Research Council of Canada, and a grant from Google to DJL.

Correspondence concerning this article should be addressed to Peter J. Rentfrow, Department of Psychology, University of Cambridge, Free School Lane, Cambridge CB2 3RQ, United Kingdom. E-MAIL: pjr39@cam.ac.uk 


\section{References}

ABrams, D. (2009). Social identity on a national scale: Optimal distinctiveness and young people's self-expression through musical preference. Group Processes and Intergroup Relations, 12, 303-317. doi: 10.1177/1368430209102841.

BerLyne, D. E. (1971). Aesthetics and psychobiology. New York: Appleton-Country-Crofts.

BEŠIć, N., \& KERR, M. (2009). Punks, Goths, and other eye-catching peer crowds: Do they fulfill a function for shy youths? Journal of Research on Adolescence, 19, 113-121.

Brown, D. E. (2004). Human universals, human nature $\&$ human culture. Daedalus, 133(4), 47-54. doi:10.1162/0011526042365645.

Cattell, R. B., \& Anderson, J. C. (1953). The measurement of personality and behavior disorders by the I.P.A.T. music preference test. Journal of Applied Psychology, 37, 446-454. doi: 10.1037/10175-008.

Cattell, R. B., \& SAunders D. R. (1954). Musical preferences and personality diagnosis: A factorization of one hundred and twenty themes. Journal of Social Psychology, 39, 3-24. doi: 10.1080/00224545.1954.9919099.

Chanda, M., \& Levitin, D. J. (2011). The neurochemistry of music: Evidence for health outcomes. Unpublished manuscript, McGill University.

Colley, A. (2008). Young people's musical taste: Relationship with gender and gender-related traits. Journal of Applied Social Psychology, 38, 2039-2055. doi: 10.1111/j.1559-1816.2008.00379.x.

Cross, I. (2001). Music, cognition, culture and evolution. Annals of the New York Academy of Sciences, 930, 28-42. doi: 10.1111/ j.1749-6632.2001.tb05723.x.

Delsing, M. J. M. H., Ter Bogt, T. F. M., Engels, R. C. M. E., \& MeEus, W. H. J. (2008). Adolescents' music preferences and personality characteristics. European Journal of Personality, 22, 109-130. doi: 10.1002/per.665.

Dunn, P. G., De Ruyter, B., \& Bouwhuis, D. G. (2012). Toward a better understanding of the relation between music preference, listening behavior, and personality. Psychology of Music, 40, 411-428.

Emery, C. F., Hsiao, E. T., Hill, S. M, \& Frid, D. J. (2003). Shortterm effects of exercise and music on cognitive performance among participants in a cardiac rehabilitation program. Heart and Lung: The Journal of Acute and Critical Care, 3(6), 368-373. doi: 10.1016/S0147-9563(03)00120-1.

George, D., Stickle, K., Rachid, F., \& Wopnford, A. (2007). The association between types of music enjoyed and cognitive, behavioral, and personality factors of those who listen. Psychomusicology, 19, 32-56.

Grewe, O., \& Kopiez, R., Altenmüller, E., (2009). The chill parameter: Goose bumps and shivers as promising measures in emotion research. Music Perception, 27, 61-74.

HaAn, N., Millsap, R., \& HartKa, E. (1986). As time goes by: Change and stability in personality over fifty years. Psychology and Aging, 1, 220-232.
Hogan, R. (1996). A socioanalytic perspective on the five-factor model. In J. S. Wiggins (Ed.), The five-factor model of personality: Theoretical perspectives (pp. 180-207). New York: Guilford Press.

Holbrook, M. B., \& SCHINDlER, R. M. (1989). Some exploratory findings on the development of musical tastes. Journal of Consumer Research, 16, 119-124.

KopaCz, M. (2005). Personality and music preferences: The influence of personality traits on preferences regarding musical elements. Journal of Music Therapy, 42, 216-239.

LeBlanc, A., Sims, W. L., SiIvola, C., \& Obert, M. (1996). Music style preferences of different age listeners. Journal of Research in Music Education, 44, 49-59.

Levitin, D. J., \& Bellugi, U. (1998). Musical ability in Individuals with Williams Syndrome. Music Perception, 15, 357-389.

Levitin, D. J., Cole, K., Chiles, M., Lai, Z., Lincoln, A., \& Bellugi, U. (2004). Characterizing the musical phenotype in individuals with Williams Syndrome. Child Neuropsychology, 10, 223-247.

McCown, W., Keiser, R., Mulhearn, S., \& Williamson, D. (1997). The role of personality and gender in preference for exaggerated bass in music. Personality and Individual Differences, 23, 543-547. doi: 10.1016/S0191-8869(97)00085-8.

McNamara, L., \& BAllard, M. E. (1999). Resting arousal, sensation seeking, and music preference. Genetic, Social, and General Psychology Monographs, 125, 229-250.

Menon, V., \& Levitin, D. J. (2005). The rewards of music listening: Response and physiological connectivity of the mesolimbic system. NeuroImage, 28(1), 175-184.

North, A. C., \& Hargreaves, D. J. (1995). Subjective complexity, familiarity, and liking for popular music. Psychomusicology, 14, 77-93.

North, A. C., \& Hargreaves, D. J. (1996). Responses to music in aerobic exercise and yogic relaxation classes. British Journal of Psychology, 87, 535-547.

North, A. C., \& Hargreaves, D. J. (1998). The effect of music on atmosphere and purchase intentions in a cafeteria. Journal of Applied Psychology, 28, 2254-2273.

North, A. C., \& Hargreaves, D. J. (2007). Lifestyle correlates of musical preference: 1 . Relationships, living arrangements, beliefs, and crime. Psychology of Music, 35, 58-87.

Rentfrow, P. J., GoldberG, L. R., \& Levitin, D. J. (2011). The structure of musical preferences: A five-factor model. Journal of Personality and Social Psychology, 100, 1139-1157.

RentFrow, P. J., GoldberG, L. R., \& ZilCA, R. (2011). Listening, watching, and reading: The structure and correlates of entertainment preferences. Journal of Personality, 79, 223-257. doi: 10.1111/j.1467-6494.2010.00662.x.

RentFrow, P. J., \& Gosling, S. D. (2003). The do re mi's of everyday life: The structure and personality correlates of music preferences. Journal of Personality and Social Psychology, 84, 1236-1256. doi: 10.1037/0022-3514.84.6.1236. 
RentFrow, P. J., \& Gosling, S. D. (2006). Message in a ballad: The role of music preferences in interpersonal perception. Psychological Science, 17, 236-242.doi: 10.1111/j.14679280.2006.01691.x.

RentFrow, P. J., \& Gosling, S. D. (2007). The content and validity of music-genre stereotypes among college students. Psychology of Music, 35, 306-326. doi: 10.1177/ 0305735607070382

Rentfrow, P. J., \& McDonald, J. A. (2009). Music preferences and personality. In P. N. Juslin \& J. A. Sloboda (Eds.), Handbook of music and emotion (pp. 669-695). Oxford, UK: Oxford University Press.

RentFrow, P. J., McDonald, J. A., \& Oldmeadow, J. A. (2009). You are what you listen to: Young people's stereotypes about music fans. Group Processes and Intergroup Relations, 12, 329-344. doi: 10.1177/1368430209102845.

RICKARD, N. S. (2004). Intense emotional responses to music: a test of the physiological arousal hypothesis. Psychology of Music, 32, 371-388. doi: 10.1177/0305735604046096.

Rickard, N. S., Toukhsati, S. R., \& Field, S. E. (2005). The effect of music on cognitive performance: Insight from neurobiological and animal studies. Behavioral and Cognitive Neuroscience Reviews, 4, 235-321. doi: 10.1177/1534582305285869.

SCHÄFer, T., \& Sedlmeier, P. (2009). From the functions of music to music preference. Psychology of Music, 37, 279-300. doi: $10.1177 / 0305735608097247$.
SchellenberG, E. G., Peretz, I., \& Vieillard, S. (2008). Liking for happy and sad sounding music: Effects of exposure. Cognition and Emotion, 22, 218-237. doi: 10.1080/02699930701350753.

SCHWARTZ, K. D., \& FouTs, G. T. (2003). Music preferences, personality style, and developmental issues of adolescents. Journal of Youth and Adolescence, 32, 205-213. doi: 10.1023/A:1022547520656.

SLOBODA, J. A. (1991). Musical structure and emotional response: Some empirical findings. Psychology of Music, 19, 110-120.

SlobodA, J. A., \& O’NeILl, S. A. (2001). Emotions in everyday listening to music. In P. N. Juslin \& J. A. Sloboda (Eds.), Music and emotion: Theory and research (pp. 415-429). Oxford, UK: Oxford University Press.

Tekman, H. G., \& Hortaçsu, N. (2002). Music and social identity: Stylistic identification as a response to musical style. International Journal of Psychology, 37, 277-285. doi: 10.1080/00207590244000043.

Williams, D. A. (1996). A study of internal validity of the instrument timbre preference test. Journal of Research in Music Education, 44, 268-277.

Zentner, M., Grandjean, D., \& Scherer, K. R. (2008). Emotions evoked by the sound of music: Characterization, classification, and measurement. Emotion, 8, 494-521. doi: 10.1037/ 1528-3542.8.4.494.

ZweigenHAFt, R. L. (2008). A do re mi encore: A closer look at the personality correlates of music preferences. Journal of Individual Differences, 29, 45-5. 
